\title{
Sociometrias territoriais de participação cidadã: mapas de Kernel como ferramenta de apoio ao planejamento estratégico municipal ${ }^{1}$
}

Territorial sociometries of citizen participation: Kernel maps as a support tool for municipal strategic planning

Paulo Castro Seixas[a] (D), Luís Baptista[a] (1), Ricardo Cunha Dias[a] (1)

[a] Universidade de Lisboa (UL), Instituto Superior de Ciências Sociais e Políticas (ISCSP), Lisboa, Portugal

Como citar: Seixas, P. C., Baptista, L., \& Dias, R. C. (2020). Sociometrias territoriais de participação cidadã: mapas de Kernel como ferramenta de apoio ao planejamento estratégico municipal. urbe. Revista Brasileira de Gestão Urbana, 12, e20190249. https://doi.org/10.1590/2175-3369.012.e20190249

\section{Resumo}

Partindo do pressuposto da necessidade de participação cidadã para um planejamento estratégico municipal mais efetivo, este artigo analisa a perceção e participação dos jovens na construção de sociometrias territoriais como novos mapas sociais. A pesquisa centra-se no concelho de Cascais como estudo de caso, recorrendo a um formulário espacial de Participação Pública com Sistema de Informação Geográfica (PPSIG) para explorar mobilidades, topofilias, topofobias, toponegligências e propostas de mudança. Para além de propor e evidenciar a aplicação de mapas de Kernel como instrumento de PPSIG, esta pesquisa corporizou os desafios que ainda se colocam à utilização destas ferramentas na passagem para Planos Diretores Municipais de 3aㅗ geração em Portugal.

Palavras-chave: Planejamento participativo. Sociometrias territoriais. Mapas de Kernel. PPSIG.

\begin{abstract}
Based on the assumption of the need for citizen participation for a more effective municipal strategic planning, this paper analyzes the perception and participation of young people in the construction of territorial sociometries as new social maps. The research focuses on the municipality of Cascais as a case study, through a spatial form of Public Participation with Geographic Information System (PPGIS) to explore mobility, topophilia, topophobia, toponegligences and proposals for change. In addition to proposing and highlighting the application of Kernel maps as a PPGIS instrument, this research embodied the challenges that still face the use of these tools in the transition to 3rd Generation Municipal Master Plans in Portugal.
\end{abstract}

Keywords: Participatory planning. Territorial sociometries. Kernel maps. PPGIS.

\footnotetext{
${ }^{1}$ Esta pesquisa é parte do projeto CRICity - AS CRIANÇAS E O SEU DIREITO À CIDADE - PTDC/SOC-SOC/30415/2017- financiado pela Fundação para a Ciência e a Tecnologia.
}

PCS é doutor em Antropologia, agregado em Sociologia, e-mail: pseixas@iscsp.ulisboa.pt

LB é licenciado em Geografia, doutorando em Geografia e Planeamento Territorial, mestre em Gestão do Território,

e-mail: luisbap@gmail.com

RCD é licenciado em Sociologia, doutorando em Administração Pública, mestre em Sociologia, e-mail: rdias@iscsp.ulisboa.pt 


\section{Introdução}

Em Portugal, o planejamento do território foi recentemente alvo de uma reforma estrutural que decorreu da publicação da Lei de Bases Gerais da Política Pública de Solos, de Ordenamento do Território e de Urbanismo (Lei no 31/2014, de 30 de maio), da entrada em vigor do novo Regime Jurídico dos Instrumentos de Gestão Territorial (Decreto-Lei no 80/2015, de 14 de maio) e legislação complementar. Um dos instrumentos que deve ser revisto e ajustado a estas novas disposições é o Plano Diretor Municipal (PDM), tendo os municípios até julho de 2020 para o fazer (Lei no 74/2017, de 16 de agosto) (Portugal, 2014, 2015, 2017).

Neste quadro, há a oportunidade para entrar naquela que tem sido referida como ' 3 a geração de PDM' (Lúcio \& Rosa, 2004). Para isso, para além da densidade construtiva e do zonamento funcional (1aa geração); e de zonas de ativação/atratividade socioeconómica muito centrada no turismo e no talento ( $2^{\text {a }}$ geração), é necessária uma atenção centrada no ambiente e um verdadeiro plano sociocultural que requer ativar a cidadania pela participação de grupos territoriais específicos nas políticas públicas (3ª geração).

Na literatura, uma nova geração de políticas territoriais tem sido discutida à luz de conceitos como 'governo aberto', 'governação integrada' e 'governança', evidenciando a necessidade de uma governação mais participada, transparente e integrada que pode ser potenciada pelo uso das novas Tecnologias de Informação e Comunicação (TIC) em grande escala (Ferrão, 2010, 2014). De facto, é hoje cada vez mais comum os governos recorrerem a ferramentas de Sistemas de Informação Geográfica (SIG) de Participação Pública baseada na Internet (PPSIG), como formas de mapeamento interativo que aumentam a participação pública e tornam o planejamento mais informado (Brown \& Kyttä, 2014; Babelon et al., 2017).

Existem já alguns trabalhos que procuraram evidenciar o potencial e utilidade do mapeamento participativo em função de ferramentas SIG (Bunch et al., 2012; Atzmanstorfer et al., 2014; Silva et al., 2017; Rzeszewski \& Kotus, 2019). No entanto, a literatura está ainda atrasada perante a rápida aplicação prática de instrumentos de PPSIG (Babelon et al., 2017). Elaborada em parceria com a Vereação do Urbanismo e o Departamento de Planejamento Estratégico (DPE) da Câmara Municipal de Cascais (CMC), esta pesquisa pretende justamente contribuir para evidenciar tal aplicação.

Dado que o planejamento implica pensar o futuro, foram considerados como sujeitos centrais nesta pesquisa os jovens deste município (alunos do Ensino Secundário). 0 objetivo foi explorar mobilidades, topofilias, topofobias, toponegligências e propostas, procurando-se atingir sociometrias territoriais em função de mapas de densidade de Kernel. Paralelamente procurou-se também discutir o potencial e os desafios à aplicação deste tipo de ferramentas no suporte à tomada de decisão e a um planejamento estratégico mais efetivo.

0 texto encontra-se organizado da seguinte forma. Uma primeira secção introduz a problemática da PPSIG no quadro da passagem de um planejamento formal para um planejamento participado, referindo alguns dos desafios já identificados pela literatura a essa transição. Numa segunda secção são apresentadas e justificadas as opções metodológicas, que funcionam também como um tutorial (passível de ser replicado por outras autarquias) da aplicação dos mapas de Kernel como instrumento de PPSIG. Segue-se uma secção de apresentação das sociometrias territoriais alcançadas e uma outra de discussão dos desafios sentidos na aplicação desta pesquisa. 0 texto termina fazendo uma síntese dos principais resultados e contributo da pesquisa.

\section{Enquadramento teórico}

Este texto tem como objeto de discussão teórica a utilização de instrumentos de PPSIG no apoio a um planejamento urbano e territorial mais efetivo. A problemática do planejamento participativo insere-se nos estudos da legibilidade urbana e das representações dos lugares que têm na Geografia Humanista o 
seu suporte. Por oposição ao 'espaço' mensurável e objetivo, o 'lugar' traduz as ligações afetivas evocadas pela relação entre cultura e ambiente natural, criando novas paisagens que ganham forma na imaginação dos indivíduos (Tuan, 1979). Tais ligações podem ser adjetivadas em função dos conceitos de topofilia (apego/segurança ao lugar), topofobia (recusa/medo do lugar) e toponegligência (ausência de significado do lugar) (Tuan, 1990, 2013).

Ao possuírem/adquirirem sentimentos sobre os lugares (sense of place), espera-se que os indivíduos adotem atitudes e ações, procurando mudanças nos seus espaços de vivências, participando nos processos decisórios e nos debates sobre as necessidades nesses lugares. Ao nível da elaboração dos PDM, tal participação implica, porém, conciliar capacidade técnica e conhecimento local. Isto significa que à tradicional 'leitura técnica' é necessário combinar uma 'leitura comunitária' condizente com a bagagem da população (Souza, 2004). Nesse sentido, tem sido alertada a necessidade de um 'planejamento de gabinete' (Souza, 2004) ser complementado por um 'planejamento de terreno' ou um 'planejamento cultural' que possibilite uma nova cultura de planejamento (Seixas, 2017), reformulando as metodologias existentes e aumentando a participação pública (Vaz \& Pereira, 2010).

Com o avanço das TIC, os instrumentos de PPSIG apresentam-se como facilitadores deste tipo de metodologias, disponibilizando ferramentas que permitem a criação de técnicas mais interativas, emancipatórias e colaborativas (Bugs \& Reis, 2016). Ao desenvolvimento destas ferramentas, tem também sido associado o conceito de Smart Cities, assentando as suas estratégias de governança na inclusão tecnológica e dos cidadãos nos processos de tomada de decisão (Goodspeed, 2015). No entanto, a literatura evidencia que os projetos de Smart Cities estão ainda longe de uma 'co-criação cidadã' (Cohen, 2015) idealizada para um planejamento integrado ao nível da cidade (Abadia et al., 2019).

Assim, apesar do potencial atribuído aos instrumentos de PPSIG, os desafios a um planejamento participativo são ainda vários. 0 primeiro e talvez maior desafio é o de criar uma cultura de participação em que o planejamento deixe de ser uma relação entre técnicos (Souza, 2004; Seixas, 2017). No contexto português, foi já demonstrado que existe uma grande dificuldade em se passar de um planejamento codificado e pericial para um place-based (Ferreira \& Seixas, 2017). Nesse quadro, a participação acaba muitas vezes por não passar de um mero apaziguamento/tokenismo (Arnstein, 1969). Um segundo desafio, mas ainda relacionado, é o da 'participação autêntica' (Ghilardi, 2001), implicando a corresponsabilização e a partilha de poderes. A esse nível, existem múltiplos constrangimentos, como o engajamento dos cidadãos; o desenvolvimento de interfaces persuasivas; a relevância atribuída por técnicos e políticos à participação pública; a capacidade dos cidadãos em participar; e as barreiras institucionais a essa participação (Bugs \& Reis, 2016).

Um outro desafio é a conciliação entre big e small data (Degbelo et al., 2016; Seixas et al., 2017). O planejamento urbano tende ainda muito a utilizar dados nos quais a perceção das pessoas é considerada de forma agregada, sendo reduzidos os casos em que há uma escuta ativa e personalizada. Um último desafio, transversal, é o da adequação dos dispositivos digitais a uma participação efetiva e a sua relação com outras metodologias. Combinar capacidade técnica e conhecimento local implica que os dados recolhidos possam ser objetivamente vertidos nos instrumentos de planejamento. Isso torna difícil a utilização de metodologias mais construtivistas (ex.: mapas mentais/cognitivos) e perpetua uma narrativa de participação baseada no potencial tecnológico sem que esse potencial, muitas vezes, se venha a realizar.

Recorrendo a um instrumento de PPSIG, esta pesquisa utilizou mapas de Kernel para procurar verter uma pluralidade de experiências de lugar num quadro de perceção objetiva a uma escala de planejamento municipal. Para além de evidenciar a aplicação de uma metodologia de participação cidadã, este exercício foi útil para discutir alguns dos desafios acima enunciados no quadro da conciliação entre leituras participadas e ação técnica e política ao nível dos PDM. 


\section{Metodologia}

Tendo como objetivo a aplicação e discussão de uma metodologia de PPSIG na construção de mapas juvenis, a pesquisa implicou o envolvimento de 8 das 17 escolas, públicas e privadas, do concelho de Cascais (Figura 1). Trata-se de um conjunto diversificado de escolas selecionado em função de integrarem já um projeto de planejamento participado dinamizado pelo DPE-CMC.

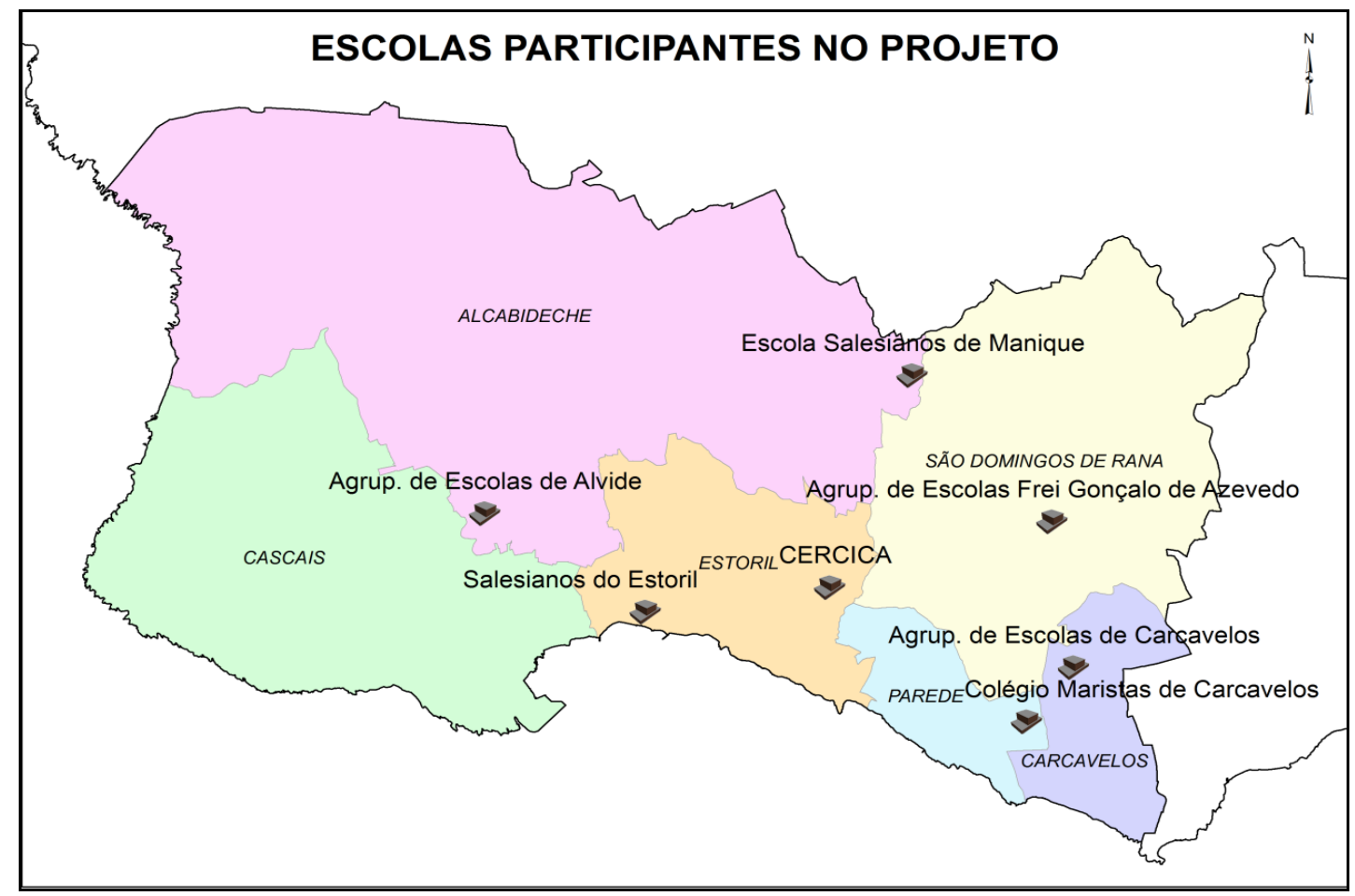

Figura 1 - Escolas participantes do projeto. Fonte: Elaboração própria.

A pesquisa teve um caráter exploratório, sustentando-se numa abordagem mista, recorrendo-se à identificação de lugares vertidos num mapa de densidades mensuráveis. Com o número de jovens interrogados (106) e o número total de lugares identificados (562) não pretendia ter uma representatividade quantitativa, mas a saturação de respostas que permitisse uma forte probabilidade em relação às escolhas indicadas (Quadro 1). A amostra dos jovens foi selecionada do universo de alunos do Ensino Secundário, correspondendo a áreas de estudo diversas e a uma faixa etária entre os $16 \mathrm{e}$ os 20 anos.

Quadro 1 - Universo de pesquisa

\begin{tabular}{|c|c|c|c|c|c|}
\hline Universo & Total & \multicolumn{2}{|c|}{ Homens } & \multicolumn{2}{c|}{ Mulheres } \\
\hline Escolas & 8 & $\sum$ & $\%$ & $\sum$ & $\%$ \\
\hline Inquiridos & 106 & 40 & $38 \%$ & 66 & $62 \%$ \\
\hline Respostas ativas & 562 & 215 & $38 \%$ & 347 & $62 \%$ \\
\hline Respostas eliminadas & 20 & 12 & $60 \%$ & 8 & $40 \%$ \\
\hline
\end{tabular}

Fonte: Elaboração própria.

Em relação ao modelo de análise, partimos de cinco conceitos-chave com base em Tuan (1990): mobilidades; topofilias, topofobias, toponegligências e propostas (Quadro 2). 
Quadro 2 - Modelo de Análise

\begin{tabular}{|c|c|c|}
\hline Conceitos & Dimensōes & Indicadores \\
\hline \multirow[b]{2}{*}{ Mobilidades } & $\begin{array}{l}\text { Mobilidade principal: fluxo } \\
\text { casa-escola }\end{array}$ & $\begin{array}{l}\text { Meio de locomoção atual casa-escola e } \\
\text { Meio de locomoção desejado casa-escola }\end{array}$ \\
\hline & $\begin{array}{l}\text { Mobilidades complementares: } \\
\text { frequências }\end{array}$ & $\begin{array}{l}\text { Lugares que frequenta sozinho e com amigos } \\
\text { (masculino/feminino) } \\
\text { Lugares que frequenta com familiares } \\
\text { (masculino/feminino) }\end{array}$ \\
\hline \multirow{2}{*}{ Topofilias } & Preferências de lugares & Lugares de que gosta (masculino/feminino) \\
\hline & Lugares de segurança & Lugares em que se sente seguro (masculino e feminino) \\
\hline \multirow[b]{2}{*}{ Topofobias } & Rejeições de lugares & Lugares de que não gosta (masculino/feminino) \\
\hline & Lugares inseguros & $\begin{array}{c}\text { Lugares em que se sente inseguro } \\
\text { (masculino e feminino) }\end{array}$ \\
\hline Toponegligências & $\begin{array}{l}\text { Zonas não referidas como } \\
\text { preferências ou como rejeições }\end{array}$ & Zonas não referidas \\
\hline \multirow{2}{*}{ Propostas } & $\begin{array}{c}\text { Propostas de mudanças em } \\
\text { lugares rejeitados }\end{array}$ & Mudanças nos lugares de que não gosta \\
\hline & $\begin{array}{c}\text { Propostas de mudanças em } \\
\text { lugares inseguros }\end{array}$ & Mudanças nos lugares de insegurança \\
\hline
\end{tabular}

Fonte: Elaboração própria.

Ao nível da mobilidade, as dimensões consideradas foram uma 'mobilidade principal' (fluxo casa-escola), uma vez que se trata de jovens em idade escolar; e uma 'mobilidade complementar' (lugares de frequência). Quanto às topofilias, foram considerados os 'lugares de preferência' (lugares de que gosta) e os 'lugares de segurança'; enquanto na topofobia considerámos a 'rejeição de lugares' (lugares de que não gosta) e os 'lugares de insegurança'. A toponegligência é caracterizada pelas 'zonas não referidas, nem como escolhas nem como rejeições'. Finalmente, em relação às propostas, consideraram-se as 'mudanças em relação aos lugares rejeitados', assim como as 'mudanças em relação aos lugares inseguros'.

A utilização do instrumento SIG incluiu um questionário com perguntas fechadas, dando origem aos mapas de Kernel, e abertas, dando origem à análise de conteúdo na base dos quadros apresentados. A recolha de dados foi feita junto das escolas, tendo sido criadas aplicações com recurso ao ArcGis Online e ao Web App Builder for ArcGIS para a administração do questionário. No sentido de conseguir isolar variáveis de análise sem a utilização de login de utilizador, foi criada uma aplicação por sexo (rapazes e raparigas) em cada escola, perfazendo um total de 16 aplicações para as 8 escolas em estudo. 0 acesso foi feito através de uma página web em que o utilizador acedeu à aplicação que correspondia à sua escola e ao seu sexo.

Ao entrar na aplicação, foi apresentada a localização da escola em questão, centrada no mapa, pedindo-se ao utilizador para marcar pontos/locais que correspondiam a cada uma das 7 questões: morada (1); mobilidade (2); topofilias (2); e topofobias (2). Para auxiliar na localização, foram apresentados como background os ortofotomapas do concelho, com nomes de referência e uma caixa de pesquisa onde o utilizador podia procurar outros nomes (ruas, localidades ou referências). Ao marcar um novo ponto, o utilizador deveria responder às questões, incluindo as qualitativas associadas aos motivos das escolhas e/ou propostas.

Para a análise dos dados, foram agregados todos os mapas referentes a cada questão, salvaguardando os campos pré-preenchidos com indicação da escola e do sexo. Sobre cada um deles foi executado um mapa de densidades de Kernel para uma grelha de saída de resolução de 100 metros, à qual foi dada uma transparência de 20\%. Foram geradas nove (9) classes de visualização por intervalos naturais. Destas, foi excluída a primeira classe para permitir que cada mancha se individualizasse por si, não apresentando assim a classe de ligação, com menor valor de densidade e permitindo a visualização do mapa de base para uma mais fácil localização dos fenómenos. Após a eliminação da classe de valor mais baixo, estas foram reorganizadas para manter as 9 classes. 0 resultado apresenta manchas de cor que variam do azul para menor densidade de ocorrências, até aos vermelhos para maior densidade. Devido ao número de respostas e de forma a manter visível as áreas destacadas, o raio para determinação da proximidade entre ocorrências foi definido para 1000 metros. $\mathrm{Na}$ análise das localizações geradas em plataformas de 
mapping, é necessário um controlo de qualidade eficaz, pois a precisão não é fácil de obter junto de um público não rotinado neste tipo de aplicações (Rzeszewski \& Kotus, 2019). Não tendo sido possível garantir esse controlo de qualidade, a análise dos pontos inseridos foi feita de forma mais alargada, muitas das vezes agregando zonas (Zona Industrial, envolvente de...) em detrimento de uma localização mais fina e específica.

A partir dos dados recolhidos foi possível apresentar uma sociometria territorial em que, antes de mais, são evidentes lugares-estrela ou lugares-centrais (de orientação positiva ou negativa); territórios de segundo nível ou lugares-secundários, porventura lugares de frequência grupal; e lugares/territórios negligenciados (zonas não escolhidas nem preteridas). Os lugares-estrela ou zonas-estrela foram identificados como aqueles em que a percentagem de resposta foi igual ou superior a 10\%. Foi possível ainda caraterizar outras sociometrias territoriais específicas por relação a cada dimensão da operacionalização de conceitos, e tal será objeto de discussão da próxima secção.

\section{Apresentação dos dados}

Os resultados globais evidenciam, desde logo, que a taxa de resposta de orientação positiva (lugares de que gostas) é muito mais elevada do que a de orientação negativa (lugares de que não gostas). Ainda que com uma diferença menor, os lugares seguros também têm uma taxa de resposta superior à dos lugares inseguros (Quadro 3). Um outro aspeto a realçar é uma certa confluência na taxa de respostas entre os locais de que se gosta (topofilias) e as mobilidades complementares (lugares de frequência sozinho ou com amigos).

Quadro 3 - Resultado global do inquérito

\begin{tabular}{|c|c|c|c|c|c|c|c|}
\hline \multirow{2}{*}{ Questōes } & \multirow{2}{*}{$\Sigma$} & \multirow{2}{*}{$\%$} & \multicolumn{2}{|c|}{ Homens } & \multicolumn{2}{|c|}{ Mulheres } & \multirow{2}{*}{ Totais } \\
\hline & & & $\Sigma$ & $\%$ & $\Sigma$ & $\%$ & \\
\hline Como vais para a escola & 106 & $13,7 \%$ & 40 & $38 \%$ & 66 & $62 \%$ & $100 \%$ \\
\hline Como gostavas de ir & 106 & $13,7 \%$ & 40 & $38 \%$ & 66 & $62 \%$ & $100 \%$ \\
\hline Locais de que gostas & 122 & $15,8 \%$ & 46 & $38 \%$ & 76 & $62 \%$ & $100 \%$ \\
\hline Locais de que não gostas & 70 & $9 \%$ & 36 & $51 \%$ & 34 & $49 \%$ & $100 \%$ \\
\hline Locais que frequentas sozinho ou com amigos & 130 & $16,8 \%$ & 44 & $34 \%$ & 86 & $66 \%$ & $100 \%$ \\
\hline Locais que frequentas com familiares & 102 & $13,2 \%$ & 35 & $34 \%$ & 67 & $66 \%$ & $100 \%$ \\
\hline Locais onde te sentes seguro & 77 & $10 \%$ & 29 & $38 \%$ & 48 & $62 \%$ & $100 \%$ \\
\hline Locais onde te sentes inseguro & 61 & $7,9 \%$ & 25 & $41 \%$ & 36 & $59 \%$ & $100 \%$ \\
\hline Totais & 774 & $100 \%$ & & & & & \\
\hline
\end{tabular}

Fonte: Dados da pesquisa.

Em relação à variável sexo (Figura 2), é curioso que, apesar de haver mais raparigas a responder, parece ser muito mais difícil para estas referirem os 'lugares de que não gostam' do que para os rapazes. Enquanto para lugares de que gostam temos 76 respostas de raparigas, para lugares de que não gostam temos apenas $34(30,9 \%)$. Nos rapazes, a diferença entre os lugares de que gostam e de que não gostam é menor ( 46 vs. 36), sendo que os lugares de que não gostam representam 43,9\%. Tal discrepância implica levantar hipóteses de investigação sobre questões de género e território: a consciência/conhecimento territorial é função do género? A topofilia/topofobia é função do género e do conhecimento territorial? etc. 


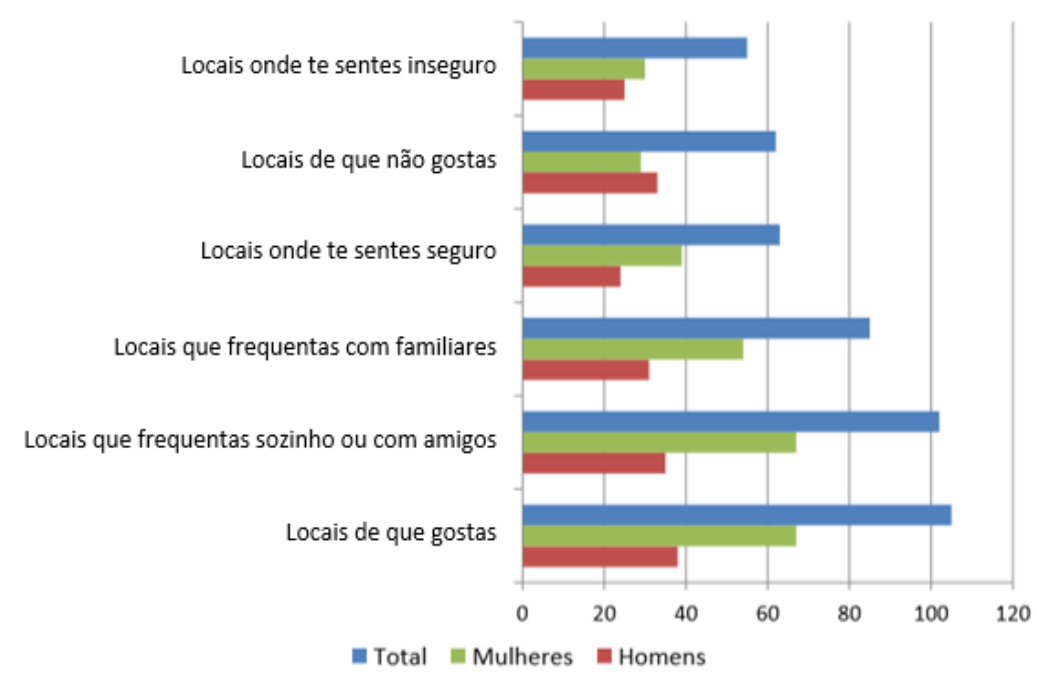

Figura 2 - Resultado global do inquérito (n. ${ }^{\circ}$ de resposta/localizações. Fonte: Dados da pesquisa.

Em relação à insegurança, poderíamos esperar que as raparigas tivessem um número de respostas superior à dos rapazes em relação a lugares de insegurança. Ora, não só as respostas em relação aos lugares em que as raparigas se sentem seguras é superior às dos lugares de insegurança, como a diferença entre raparigas e rapazes em relação aos lugares de insegurança é relativamente baixa. É possível que os rapazes arrisquem mais e que, por isso, tenham mais consciência dos lugares de insegurança. Mas poderá haver outras explicações.

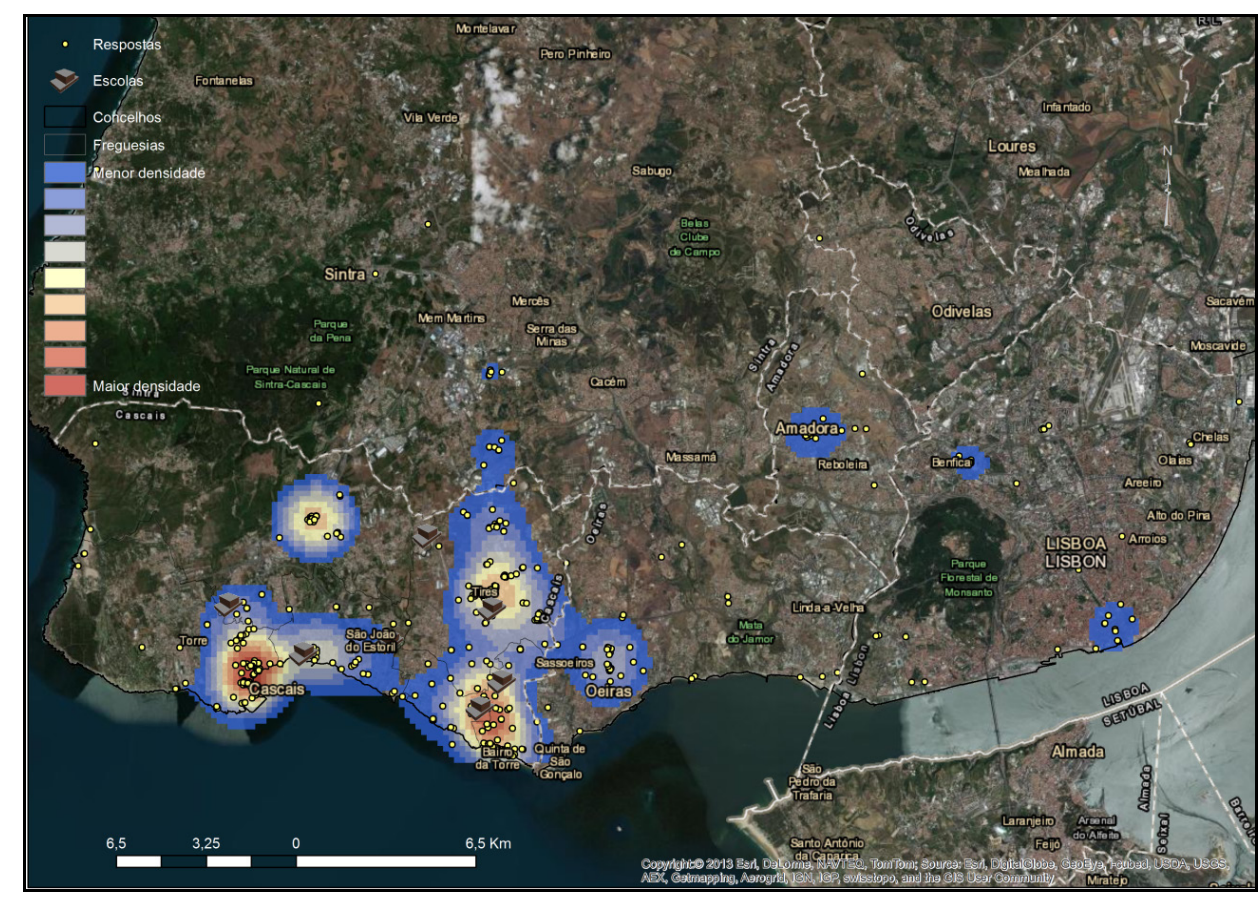

Figura 3 - Total de respostas (exceto local de residência). Fonte: Dados da pesquisa.

O total de respostas da pesquisa (Figura 3) dá-nos, desde logo, uma sociometria territorial: as perguntas com maior taxa de resposta são "Locais que frequentas sozinho ou com amigos" e "Locais de que gostas", evidenciando que tais perguntas são as que mais interessam aos inquiridos. Por outro lado, se atentarmos no mapa geral de densidades de Kernel atingido, temos claramente uma sociometria juvenil, ou seja, quais os lugares mais referidos (topofilias e topofobias) e as zonas não referidas (toponegligências). Todo o território de Cascais pode ser analisado em função dessas duas perceções-limite: uma forte intensidade de escolha 
(cuja orientação pode ser tanto positiva como negativa, ou ambas); e zonas sem qualquer referência em termos de perceção do grupo. Para além disso, é também claro que a vivência deste grupo não se confina ao concelho, sendo referidos outros lugares/territórios-de-extensão (Parque dos Poetas, em Oeiras, ou a zona da BaixaChiado, em Lisboa).

Apesar de no mapa de Kernel se poderem identificar várias zonas com alta densidade de respostas (a vermelho), a verdade é que a única zona com mais de 10\% de respostas é a Baía de Cascais. No Quadro 4 apresentam-se também os lugares ou zonas de segundo nível.

Quadro 4 - Sociometria territorial básica

\begin{tabular}{|c|c|c|}
\hline QUESTÃO & Total & Local \\
\hline \multirow{4}{*}{ TODAS AS QUESTÕES } & \multirow{4}{*}{470} & Baía de Cascais - Zona-estrela $\star$ \\
& & Cascais Shopping \\
\cline { 3 - 3 } & & Praia de Carcavelos \\
\cline { 3 - 3 } & & Envolvente ao Colégio Marista de Carcavelos \\
\cline { 3 - 3 } & & Jardins do Casino Estoril \\
\cline { 3 - 3 } & & Zona Industrial de Tires (McDonalds/Burguer King) \\
\cline { 3 - 3 } & & Parque dos Poetas (Oeiras) \\
\cline { 3 - 3 } & & Alto de Polima \\
\hline
\end{tabular}

Fonte: Dados da pesquisa.

\section{Mobilidades}

Nas mobilidades utilizaram-se duas dimensões de análise, considerando-se uma mobilidade central (fluxo casa-escola) e mobilidades complementares (lugares mais frequentados). Em relação ao fluxo casa-escola (Quadro 5), um dos resultados é que não só cerca de metade dos jovens inquiridos vai para a escola de carro (46,2\%), como uma maioria gostaria de ir de carro (56\%). Em relação aos transportes públicos (autocarro e comboio), 29,2\% dos jovens inquiridos usam esses meios para fazer o percurso casa-escola, mas, quando interrogados sobre a mobilidade desejada, só 10,4\% utilizariam os transportes públicos.

Quadro 5 - Mobilidades (fluxo casa-escola real e desejado)

\begin{tabular}{|c|c|}
\hline Como vais para a escola & Como gostavas de ir \\
\hline Não responde (1\%) & Não responde (1\%) \\
\hline \multirow{5}{*}{ Carro $(46,2 \%)$} & Carro $(67,3 \%)$ \\
\hline & Bicicleta (14,3\%) \\
\hline & A pé $(8,2 \%)$ \\
\hline & Autocarro $(6,1 \%)$ \\
\hline & Outro (4\%) \\
\hline \multirow{5}{*}{ Autocarro $(23,6 \%)$} & Carro (56\%) \\
\hline & Bicicleta (16\%) \\
\hline & Autocarro (12\%) \\
\hline & Comboio (8\%) \\
\hline & Microcar (4\%) \\
\hline \multirow{5}{*}{ A pé (22\%) } & A pé $(39,1 \%)$ \\
\hline & Carro (35\%) \\
\hline & Bicicleta (13\%) \\
\hline & Autocarro (9\%) \\
\hline & $\operatorname{Mota}(4,3 \%)$ \\
\hline \multirow{3}{*}{ Comboio (6\%) } & Carro $(66,7 \%)$ \\
\hline & Comboio (17\%) \\
\hline & Bicicleta (17\%) \\
\hline \multirow{2}{*}{ Bicicleta (2\%) } & Carro (50\%) \\
\hline & Bicicleta (50\%) \\
\hline
\end{tabular}

Fonte: Dados da pesquisa. 
Nas mobilidades suaves, só $12,3 \%$ dos jovens afirmam que gostariam de ir a pé para a escola, e 15\% de bicicleta. Evidencia-se, assim, uma grande centralidade no carro e na dependência que os jovens têm em relação aos familiares na mobilidade casa-escola-casa. Tal resultado pode estar associado a vários fatores: a disponibilidade dos pais (quando são os pais os motoristas); a autonomia (quando são os próprios jovens quem conduz, uma vez que vários jovens têm mais de 18 anos); a rapidez; e o valor do estatuto social associado ao carro. Por outro lado, o valor da autonomia é evidenciado pelo facto de um jovem (certamente sem idade para carta) ter respondido que gostava de ir de microcar. É também preciso frisar que, apesar de só dois jovens irem de bicicleta para a escola, há 15\% de jovens que gostariam de usar esse meio de transporte para o efeito.

Em relação aos lugares mais frequentados (Figura 4 e Figura 5), estabeleceu-se uma diferença entre os frequentados apenas pelo sujeito ou em companhia de pares/amigos e os frequentados na companhia de familiares.

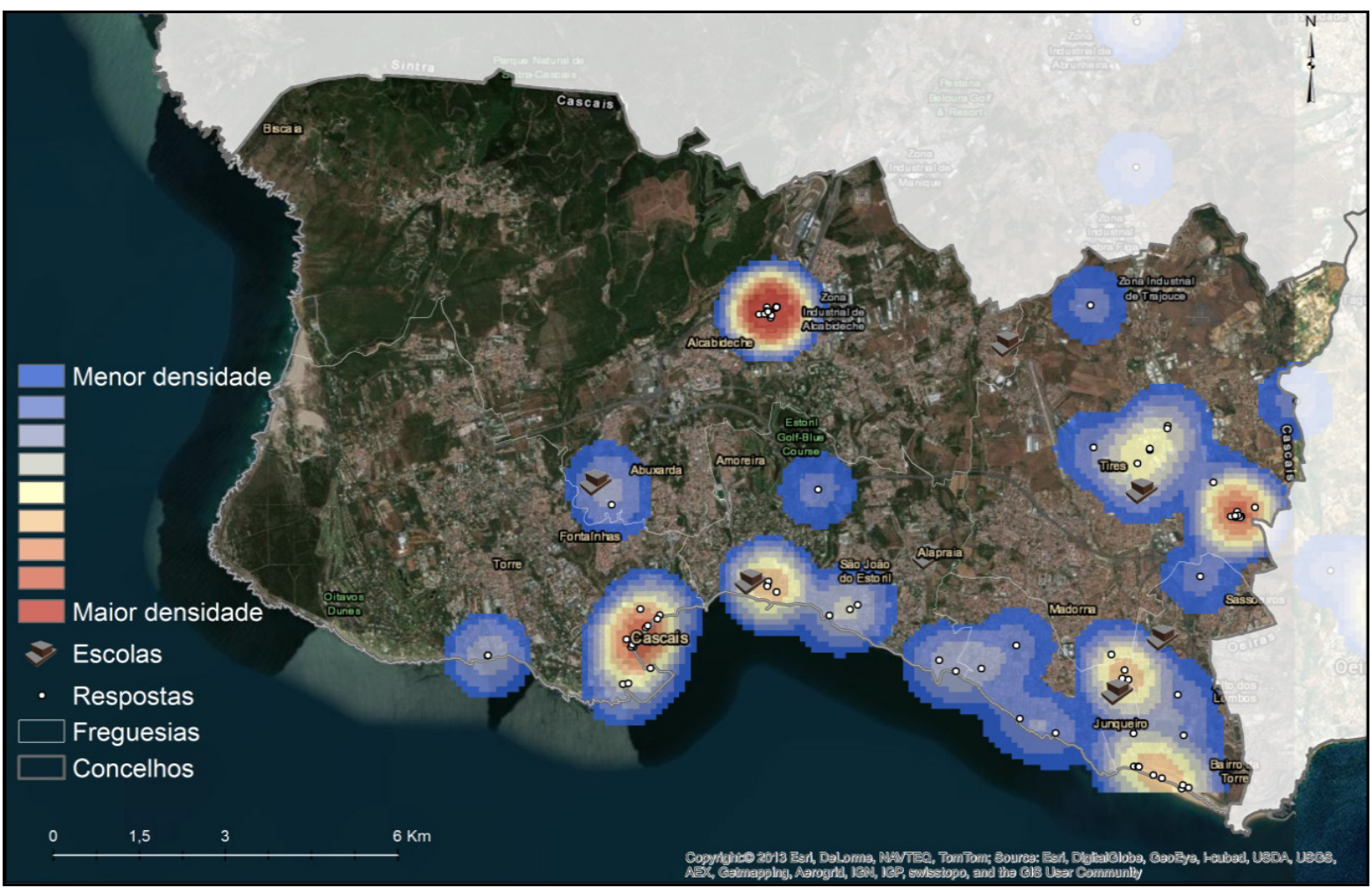

Figura 4 - Mobilidades 1 - Locais que frequentas sozinho ou com amigos. Fonte: Dados da pesquisa.

Na sociabilidade entre pares, há um lugar-estrela e uma zona-estrela: o Cascais Shopping e a Baía de Cascais. Há depois um número relativamente diminuto de lugares/zonas de segundo nível, eventualmente de frequência grupal. 


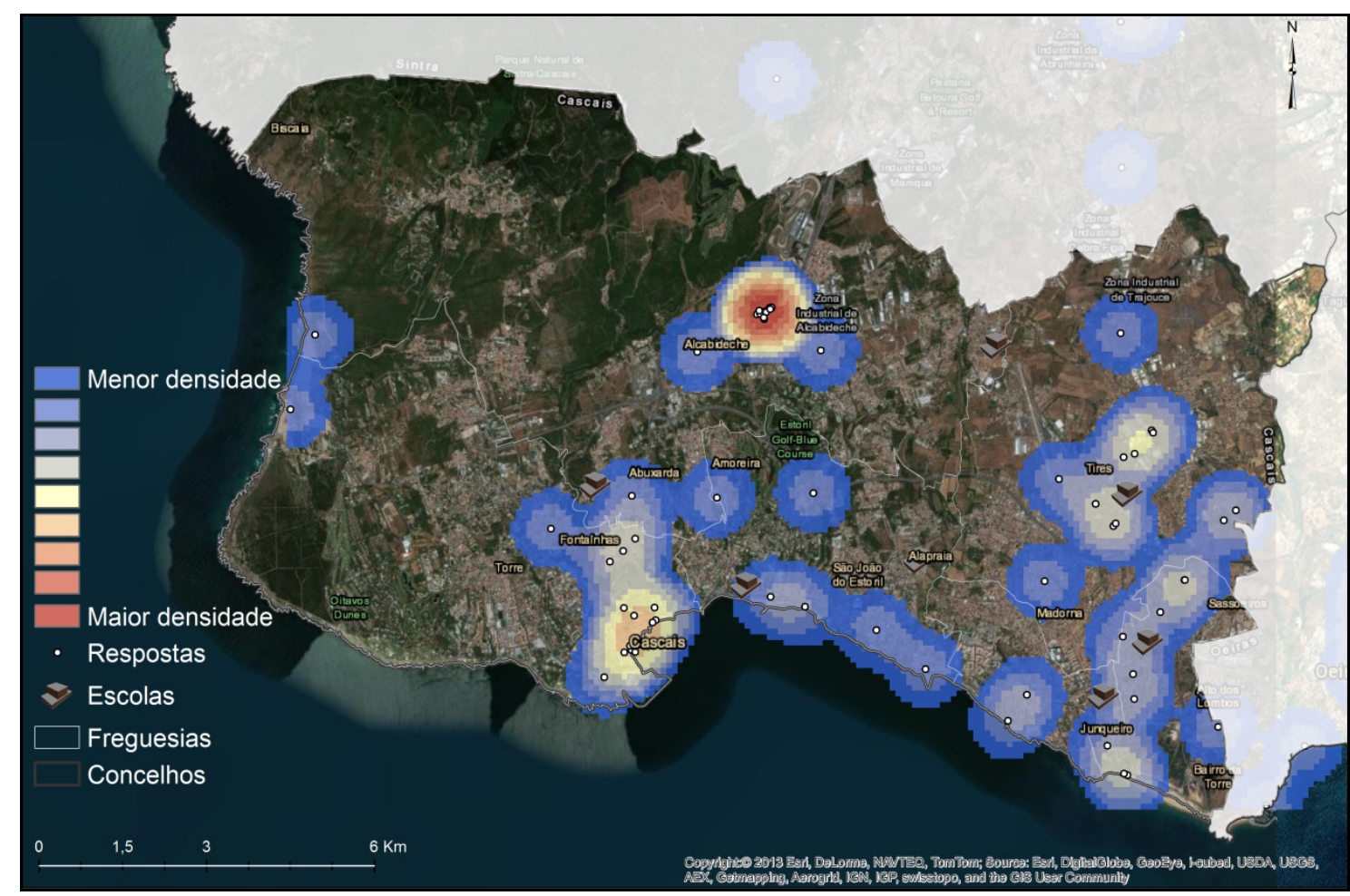

Figura 5 - Mobilidades 2 - Locais que frequentas com familiares. Fonte: Dados da pesquisa.

Quanto à sociabilidade com familiares, curiosamente o lugar-estrela e a zona-estrela repetem-se em relação à sociabilidade entre pares, ou seja, o Cascais Shopping e a Baía de Cascais (Quadro 6).

Quadro 6 - Sociometria territorial de pares

\begin{tabular}{|c|c|}
\hline QUESTÃO & Local \\
\hline \multirow{3}{*}{$\begin{array}{c}\text { LOCAIS DE FREQUÊNCIA } \\
\text { SOZINHO/AMIGOS }\end{array}$} & Cascais Shopping-Lugar-estrela $\star$ \\
\cline { 2 - 2 } & Baía de Cascais - Zona-estrela $\star$ \\
\cline { 2 - 2 } & Praia de Carcavelos \\
\cline { 2 - 2 } & Alto de Polima \\
\cline { 2 - 2 } & Zona Industrial Tires (McDonalds/Burguer King) \\
\hline
\end{tabular}

Fonte: Dados da pesquisa.

Pode-se, no entanto, construir duas sociometrias territoriais diferenciadas, ainda que haja lugares de sobreposição que interligam as duas sociometrias. Sozinhos ou com amigos, a circulação é feita em pontos de encontro localizados (Cascais Shopping, cadeias de fast-food, Baía de Cascais, jardins e praias) por serem espaços onde dá para estar com amigos e comer. A circulação com familiares segue o mesmo princípio (Quadro 7), mas por locais mais dispersos e com boa paisagem (sol, mar, natureza).

Quadro 7 - Sociometrias territoriais de familiares

\begin{tabular}{|c|c|}
\hline QUESTÃO & Local \\
\hline LOCAIS DE FREQUÊNCIA & Cascais Shopping-Lugar-estrela $\star$ \\
COM FAMILIARES & Baía de Cascais - Zona-estrela $\star$ \\
\cline { 2 - 2 } & Zona Industrial Tires (McDonalds/Burguer King) \\
\cline { 2 - 2 }
\end{tabular}

Fonte: Dados da pesquisa.

O convívio e o consumo são as razões que mais surgem para a frequência de determinados locais (Quadro 8), sendo o convívio mais relevante nos que se frequenta sozinho ou com amigos; e o consumo nos frequentados com familiares. Esta tendência é normal, pois os jovens, não tendo rendimentos 
próprios, são muitas vezes acompanhados dos pais para a aquisição de produtos como vestuário. Em ambos os casos (amigos e familiares), a referência a razões genéricas surge em terceiro lugar.

Quadro 8 - Razões para a frequência de lugares com amigos e familiares

\begin{tabular}{|c|c|c|c|}
\hline \multicolumn{2}{|l|}{ Lugares que frequenta só ou com amigos } & \multicolumn{2}{|l|}{ Lugares que frequenta com familiares } \\
\hline Razões de frequência & $\Sigma$ & Razōes de frequência & $\Sigma$ \\
\hline $\begin{array}{l}\text { Convívio/estar com amigos/ponto de } \\
\text { encontro com amigos }\end{array}$ & 24 & Comer, compras e cinema & 21 \\
\hline $\begin{array}{l}\text { Genérico: Gosto/é giro/é porreiro/gosto do } \\
\text { ambiente/é agradável/bom ambiente/bonito }\end{array}$ & 20 & Passear com a família & 15 \\
\hline Compras/cinema/comer & 17 & $\begin{array}{c}\text { Genéricos: porque } \\
\text { sim/gosto/giro/agradável/nice/ótimo local de } \\
\text { convívio }\end{array}$ & 14 \\
\hline Desporto/jogar à bola/Ténis/ver futebol & 9 & $\begin{array}{l}\text { Casa própria ou de familiares (avós, tios, irmãos) } \\
\text { ou porque os familiares vivem lá ou por ser perto } \\
\text { de casa. A casa como referência ou ponto de } \\
\text { encontro }\end{array}$ & 11 \\
\hline Praia/Piscina & 8 & Paisagem/espaços verdes/ vistas/bonito & 8 \\
\hline $\begin{array}{c}\begin{array}{c}\text { Espaços verdes/Boas vistas/paisagem/ar puro } \\
\text { e sol }\end{array} \\
\end{array}$ & 5 & Ambiente familiar & 7 \\
\hline Casa/perto de casa/acessível & 5 & Porque os familiares gostam & 4 \\
\hline Escola & 4 & Desporto/ver futebol & 3 \\
\hline Lazer/diversão & 4 & Praia/mar/piscina & 3 \\
\hline $\begin{array}{l}\text { A minha localidade/onde nasci/vou desde } \\
\text { pequeno }\end{array}$ & 3 & Calmo/tranquilo/seguro & 3 \\
\hline Sossegado/tranquilo/seguro & 3 & Local de trabalho de familiares & 2 \\
\hline Outros & 16 & Outros & 11 \\
\hline Não responde & 12 & Não responde & 0 \\
\hline Total & 130 & Total & 102 \\
\hline
\end{tabular}

Fonte: Dados da pesquisa.

Porém, surgem depois diferenças. Enquanto sozinho ou com amigos, as razões são o desporto, seguida de praia ou piscina e espaços verdes; já com familiares, os lugares são explicáveis em função de a casa própria ou de familiares se constituir como ponto de referência, seguindo-se razões associadas aos espaços verdes, ao facto dos familiares gostarem e o jovem os seguir e, só depois, o desporto e a praia. Os espaços calmos e tranquilos, assim como o local de trabalho de familiares, constituem também razões dos locais que se frequentam com familiares.

\section{Topofilias e topofobias}

Em relação às topofilias e topofobias, identificaram-se duas dimensões centrais: a preferência/rejeição e a (in)segurança. Em relação às preferências e rejeições, os mapas de Kernel (Figura 6 e Figura 7) evidenciam que os locais de preferência são mais preenchidos do que os das rejeições. Tal pode significar um maior consenso em relação às rejeições e uma maior individualização nas preferências. 


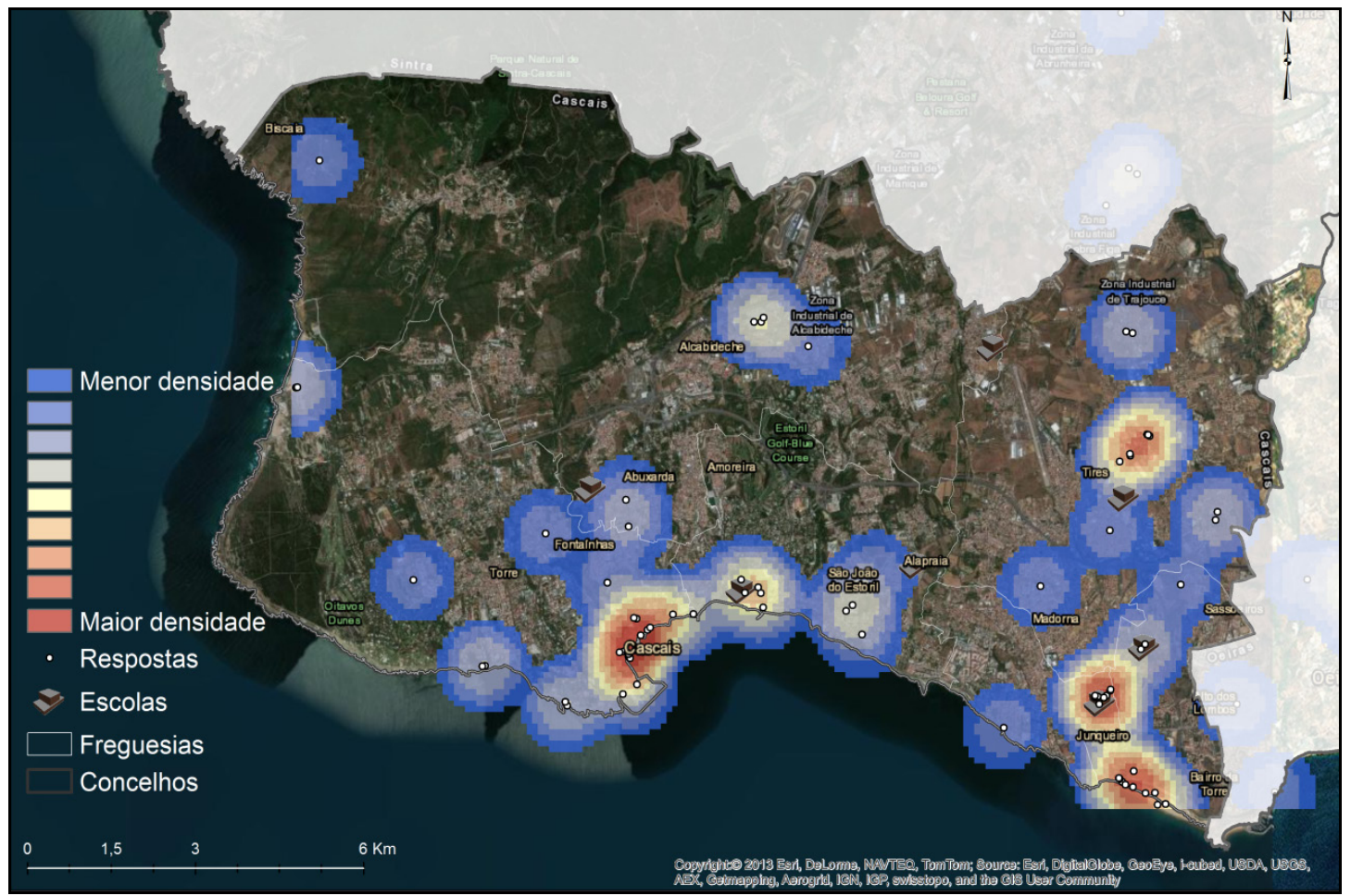

Figura 6 - Topofilias 1 - Locais de que gostas. Fonte: Dados da pesquisa.

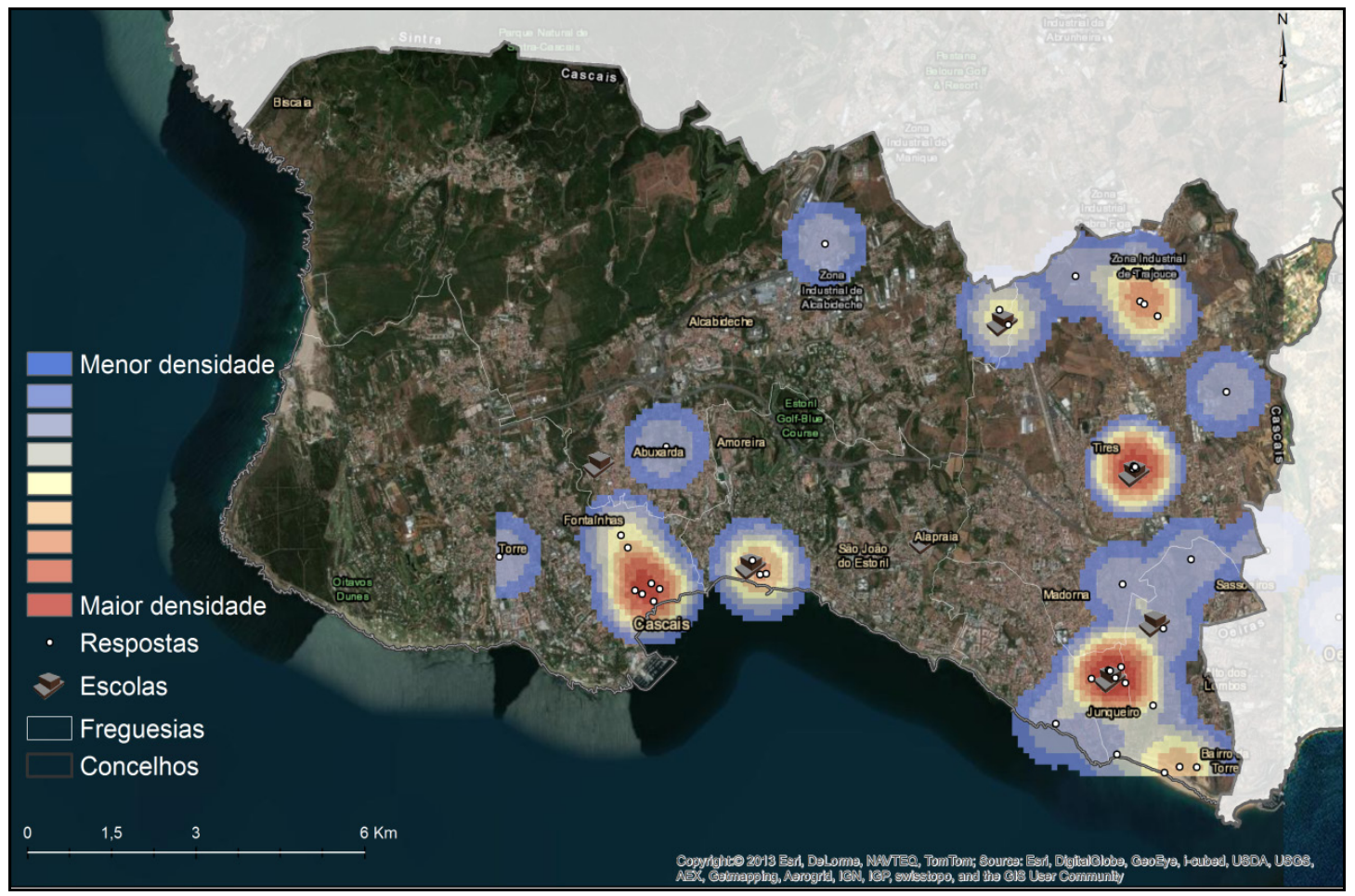

Figura 7 - Topofobias 1 - Locais de que não gostas. Fonte: Dados da pesquisa.

Os locais preferidos são aqueles por onde circulam com os amigos, onde conversam, praticam desporto, estão em esplanadas. Já os locais menos preferidos centram-se em grande parte nas escolas (geracional) e em zonas com pouca iluminação (interior de Cascais e Estoril). Na Zona Industrial de Trajouce queixam-se das pessoas que lá circulam, bem como a velocidade dos carros. Como veremos de seguida, na sociometria territorial de (in)segurança, as escolas são zonas de paradoxo: os jovens referem-nas como lugares de que 
'não gostam', mas, ao mesmo tempo, como locais seguros. Consoante as dimensões em análise, as escolas são, assim, locais topofóbicos e topofílicos em simultâneo.

Quadro 9 - Sociometrias territoriais de preferência (locais)

\begin{tabular}{|c|}
\hline Baía de Cascais - Zona-estrela $\star$ \\
\hline Praia de Carcavelos- Zona-estrela $\star$ \\
\hline Envolvente Colégio Marista Carcavelos \\
\hline Zona Industrial Tires (McDonalds/Burguer King) \\
\hline Jardins Casino Estoril \\
\hline Cascais Shopping \\
\hline
\end{tabular}

Fonte: Dados da pesquisa.

Quadro 10 - Sociometrias territoriais de rejeição (locais)

Envolvente Colégio Marista Carcavelos - Zona-estrela $\star$

Jumbo/Cascais Villa/ Estação

Zona Industrial de Trajouce

Escola Frei Gonçalves de Azevedo

Bairro da Torre

Envolvente aos Salesianos do Estoril

Fonte: Dados da pesquisa.

Em termos específicos de sociometrias territoriais, há que referir a diferença na quantidade de respostas: só cerca de $2 / 3$ dos inquiridos responderam à questão relativa aos 'locais de que não gostam', podendo significar uma maior dificuldade em identificar lugares de rejeição. Quanto às preferências (Quadro 9), podem-se identificar duas zonas-estrela: a Baía de Cascais e a Praia de Carcavelos. Já em relação à sociometria territorial de rejeição (Quadro 10), a envolvente ao colégio Marista de Carcavelos é a única zona-estrela a surgir como zona de rejeição. No entanto, esta é também uma zona de preferência, sendo provável, por isso, que haja lugares de preferência e de rejeição na envolvente a esta escola que só uma análise mais aprofundada poderá caracterizar.

As razões para não se gostar de um determinado lugar são várias (Quadro 11). ‘Confusão' é um dos termos usados, mas é usado de forma generalista, tanto associado a barulho, como a 'mau ambiente' e a 'drogas'.

Quadro 11 - Razões para a preferência e rejeição de lugares (topofilia e topofobia de gosto)

\begin{tabular}{|c|c|c|c|}
\hline \multicolumn{2}{|c|}{ Lugares de que gostas } & $\Sigma$ & \multicolumn{2}{c|}{ Lugares de que não gostas } & $\Sigma$ \\
\hline Razões de preferência & 19 & $\begin{array}{c}\text { Frequência do espaço: em geral (mau ambiente/ mal } \\
\text { frequentado); e particular (maconheiros; moradores } \\
\text { ilegais; carteiristas; ciganos) }\end{array}$ & 26 \\
\hline $\begin{array}{c}\text { Convívio/socializar com amigos } \\
\text { Genérico: porque sim/ fixe/ agradável/ } \\
\text { bom ambiente/ }\end{array}$ & 18 & $\begin{array}{c}\text { Problemas urbanísticos vários: escuro; sujidade; má } \\
\text { utilização de espaços; edifício antigo; Zona morta/ } \\
\text { vazia/ sem nada; bomba de gasolina ao pé de uma } \\
\text { escola; trânsito/ velocidade dos carros }\end{array}$ & 13 \\
\hline Praia/sol/piscina & 14 & Inseguro/ perigoso/ & 8 \\
\hline $\begin{array}{c}\text { Paisagem/ vistas/ Local bonito/ espaços } \\
\text { verdes/ pôr do sol }\end{array}$ & 12 & Confuso/ barulhento & 3 \\
\hline Comer, cafés/ bares, cinema e compras & 11 & Outros & 11 \\
\hline Desporto & 7 & Total & 70 \\
\hline Calmo/ seguro/ tranquilo & 5 & & \\
\hline Razões sexuais & 4 & & \\
\hline Encontro com familiares & 2 & & \\
\hline Consumos de drogas & 2 & & \\
\hline Passear & 2 & & \\
\hline Outros & 16 & & \\
\hline Não responde & 10 & & \\
\hline Total & 122 & & \\
\hline
\end{tabular}

Fonte: Dados da pesquisa. 
A segunda dimensão de topofobia e topofilia é a (in)segurança (Figura 8 e Figura 9). Em relação a esta dimensão, o número de respostas foi entre $2 / 3$ (segurança) e 1/2 (insegurança) dos inquiridos. Tal facto requer interpretações: evidência do cansaço dos respondentes; dificuldade em identificar espaços seguros e inseguros; etc. Para além disso, houve uma fragmentação das respostas especificamente quanto à insegurança, não sendo possível identificar um lugar ou uma zona-estrelas de insegurança (Quadros 12 e 13).

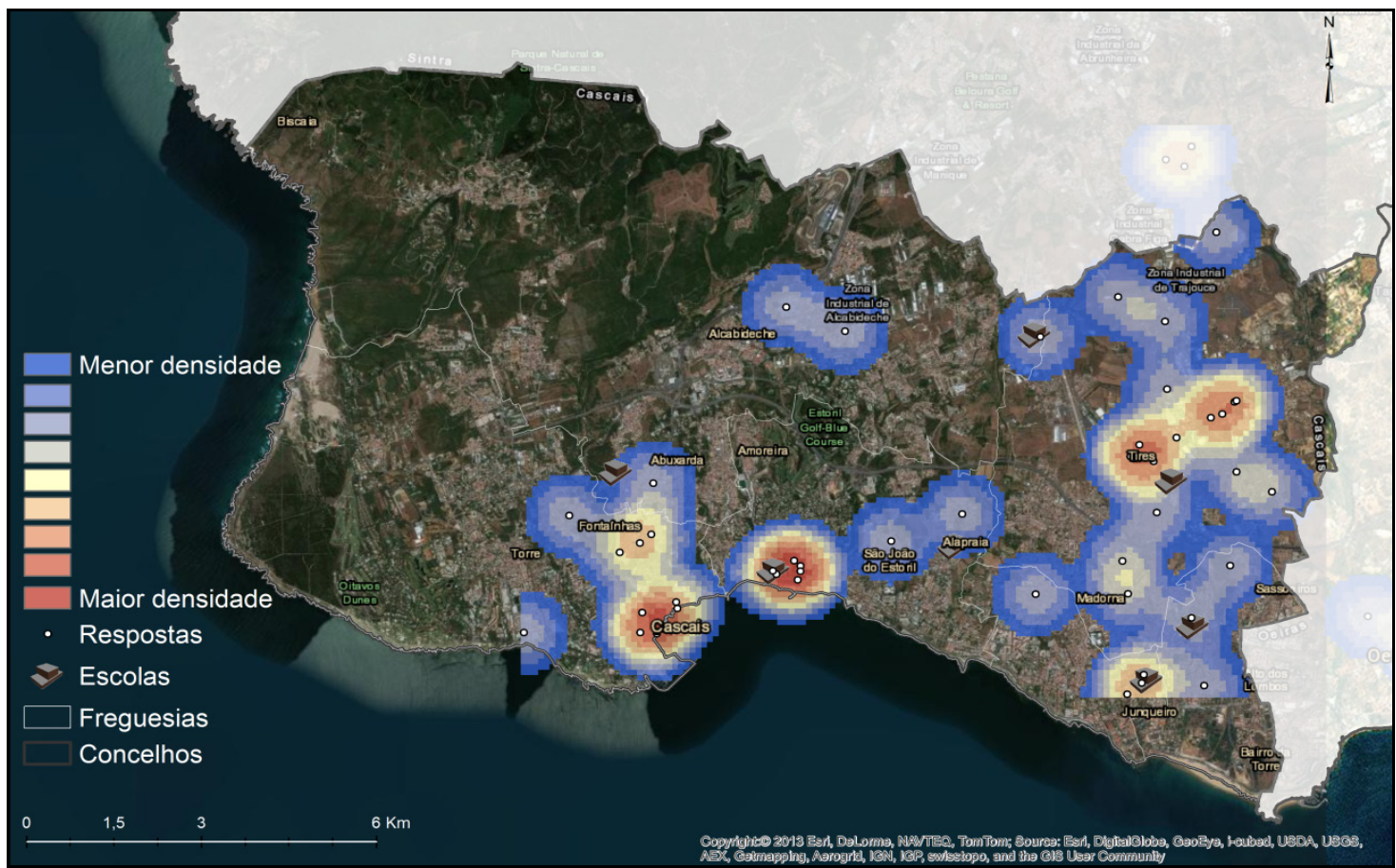

Figura 8 - Topofilias 2 - Locais onde te sentes seguro. Fonte: Dados da pesquisa.

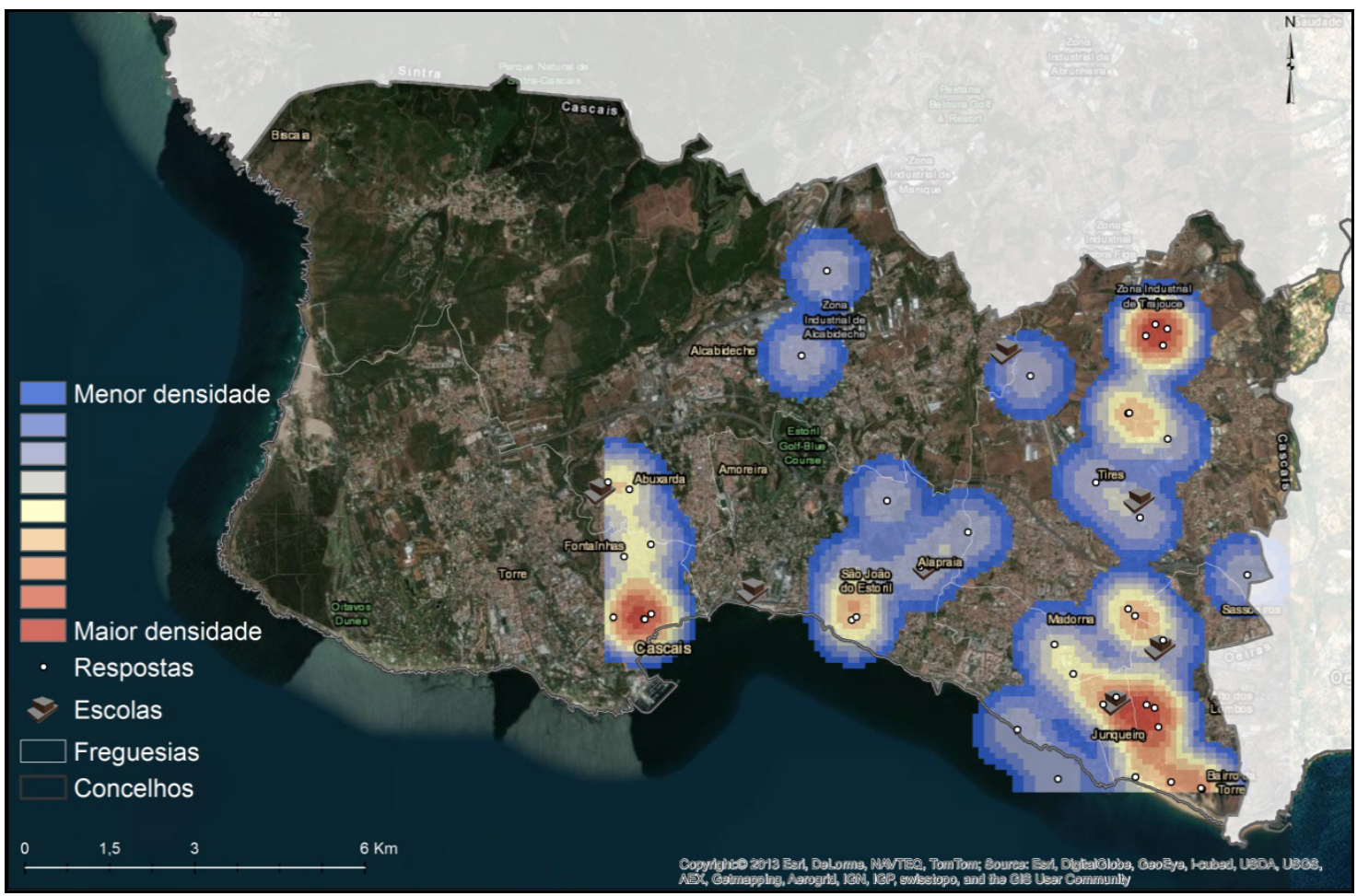

Figura 9 - Topofobias 2 - Locais onde te sentes inseguro. Fonte: Dados da pesquisa. 
A zona-estrela de segurança é a zona industrial de Tires, sendo referidos como lugares centrais os estabelecimentos de fast-food. Há uma certa sobreposição entre zonas de rejeição e zonas de insegurança, enfatizando assim lugares/zonas topofóbicas para os jovens: particularmente a zona industrial de Trajouce (o ambiente é inseguro, mas a existência de uma esquadra da PSP transmite segurança); a zona do Cascais Villa/Jumbo (que está numa zona aprazível, mas em que o abandono dos espaços comerciais transmite insegurança) e uma zona de Carcavelos (que estando ao pé da praia, encontra-se isolada, nomeadamente a zona de estacionamento e terminal rodoviário).

Quadro 12 - Sociometria territorial de segurança (local)

Zona Industrial Tires (McDonalds/Burguer King) - Zona-estrela $\star$

Centro e Baía de Cascais

Jardins do Casino Estoril

Salesianos do Estoril

Fonte: Dados da pesquisa.

Quadro 13 - Sociometria territorial de insegurança (local)

\begin{tabular}{|c|}
\hline Zona Industrial Trajouce \\
\hline Carcavelos \\
\hline Jumbo/ Cascais Villa \\
\hline S. João do Estoril \\
\hline Abuxarda \\
\hline
\end{tabular}

Fonte: Dados da pesquisa.

Em síntese (Quadro 14), a segurança é transmitida pelas escolas, pela casa de família e pelas zonas perto de casa (zonas de conforto), seguidas pelas zonas de fast-food e zonas com muita gente e passeios largos. Já os principais fatores de insegurança são a falta de iluminação, passeios estreitos e o tipo de pessoas que frequenta os espaços.

Quadro 14 - Razões para a preferência e a rejeição de lugares (topofilia e topofobia de segurança)

\begin{tabular}{|c|c|c|c|}
\hline \multicolumn{2}{|l|}{ Lugares de Segurança } & \multicolumn{2}{|l|}{ Lugares de Insegurança } \\
\hline Razões de preferência & $\Sigma$ & Razões de rejeição & $\bar{\Sigma}$ \\
\hline $\begin{array}{l}\text { A própria casa (porque é a minha casa; porque a } \\
\text { família está por perto) }\end{array}$ & 21 & $\begin{array}{l}\text { Tipo de frequência em geral (mal } \\
\text { frequentado); e em particular (negros; ciganos; } \\
\text { drogados; pessoas más; pedófilos; carteiristas) }\end{array}$ & 23 \\
\hline $\begin{array}{l}\text { Tem uma esquadra; tem policiamento; tem } \\
\text { segurança; sinto-me protegido }\end{array}$ & 10 & Perigoso à noite/ pouca iluminação/ escura & 11 \\
\hline $\begin{array}{l}\text { Um zona familiar, a zona onde cresci, onde estão } \\
\text { familiares e amigos }\end{array}$ & 7 & $\begin{array}{c}\text { Insegurança em geral/falta de } \\
\text { policiamento/sentimento de insegurança/falta } \\
\text { de proteção/não se sabe o que se pode } \\
\text { encontrar }\end{array}$ & 10 \\
\hline $\begin{array}{c}\text { Ambiente acolhedor/sem confusões/lugar } \\
\text { tranquilo/calmo }\end{array}$ & 7 & $\begin{array}{c}\text { Problemas urbanísticos: bairro social: estrada } \\
\text { estreita/perigo de atropelamento/ } \\
\text { Madorna/desorganização as ruas }\end{array}$ & 7 \\
\hline Muita gente, muitas coisas; bem frequentado & 6 & Outros & 10 \\
\hline $\begin{array}{c}\text { A escola (proteção dos funcionários; segurança } \\
\text { em relação a pessoas de fora; etc.) }\end{array}$ & 5 & Total & 61 \\
\hline Porque é um espaço indoor & 2 & & \\
\hline Outros & 9 & & \\
\hline Não responde & 10 & & \\
\hline Total & 77 & & \\
\hline
\end{tabular}

Fonte: Dados da pesquisa.

Em relação à segurança e insegurança, considerou-se ainda que a variável género poderia ser uma variável mediadora (Figura 10 e Figura 11). 


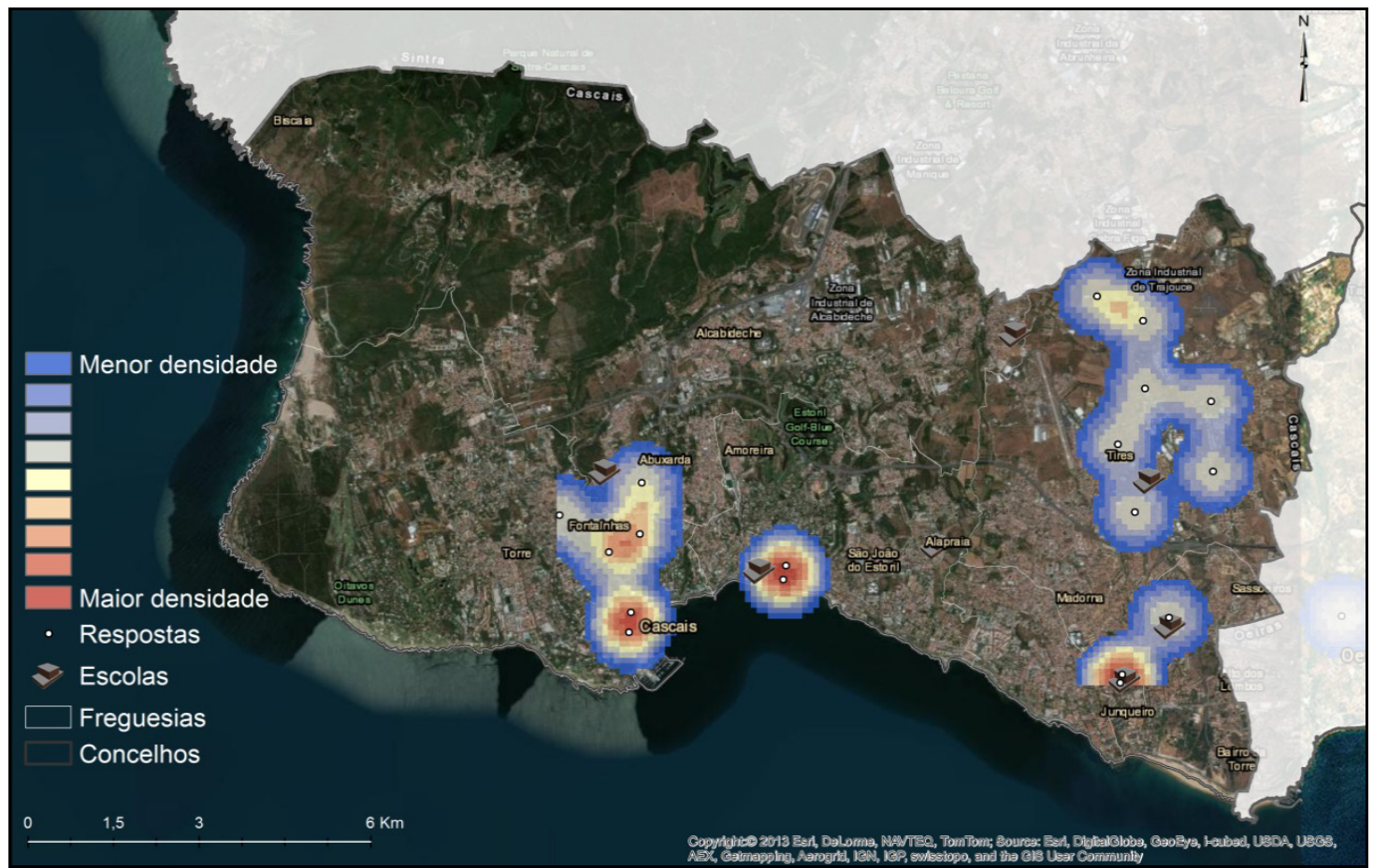

Figura 10 - Topofilias 3 - Locais onde te sentes seguro (masculino). Fonte: dados da pesquisa.

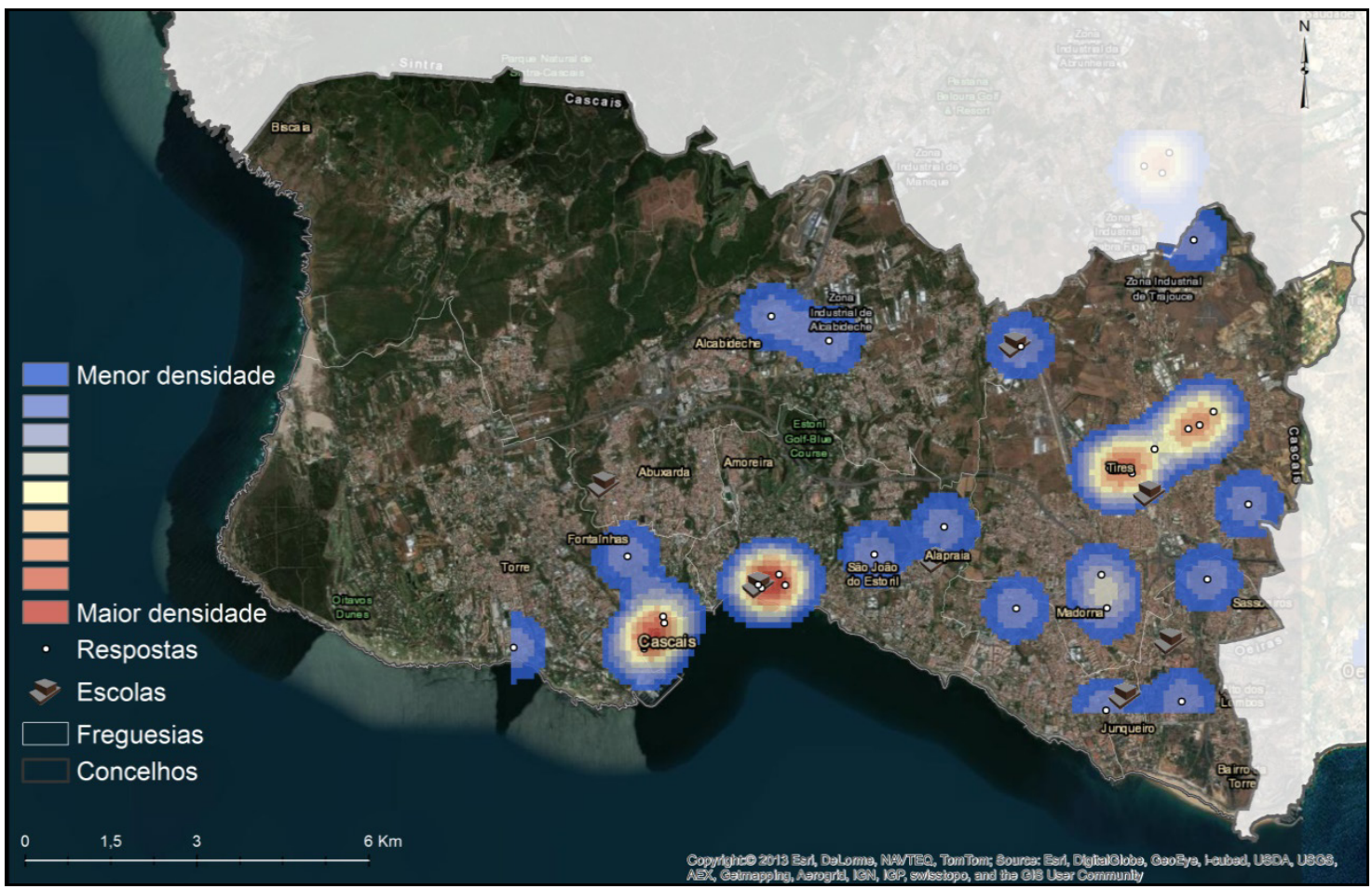

Figura 11 - Topofilias 4 - Locais onde te sentes seguro (feminino). Fonte: Dados da pesquisa.

Da análise do mapa de densidades, é claro que os rapazes têm uma perspectiva de segurança mais concentrada do que as raparigas, cujos dados são mais dispersos. Embora os Jardins do Casino Estoril e a zona da Baía e Vila de Cascais sejam patentes em ambos os géneros, há uma maior repetição destes por parte das raparigas, o que, no género feminino, permite identificá-los como zonas-estrela. A zona do Jumbo/Cascais Villa é a que é mais percecionada como zona de insegurança (Quadro 15 e Quadro 16). 
Quadro 15 - Sociometrias territoriais de segurança masculina (locais)

\begin{tabular}{|c|}
\hline Jardins do Casino Estoril \\
\hline Vila de Cascais \\
\hline Colégio Marista de Carcavelos \\
\hline
\end{tabular}

Fonte: Dados da pesquisa.

Quadro 16 - Sociometrias territoriais de segurança feminina (locais)

\begin{tabular}{|c|}
\hline Zona Industrial Tires (McDonalds/Burguer King) - Zona-estrela $\star$ \\
\hline Vila e Baía de Cascais - Zona-estrela $\star$ \\
\hline Jardins do Casino Estoril \\
\hline Escola Salesianos do Estoril \\
\hline
\end{tabular}

Fonte: Dados da pesquisa.

Por outro lado, a interpretação para tal dispersão não parece fácil. No entanto, da análise das razões para a segurança, muitas das raparigas referem que escolheram aquele local porque é a sua casa. Assim, o facto de as raparigas escolherem mais a casa como local de segurança do que os rapazes pode ser uma das explicação possível para tal dispersão.

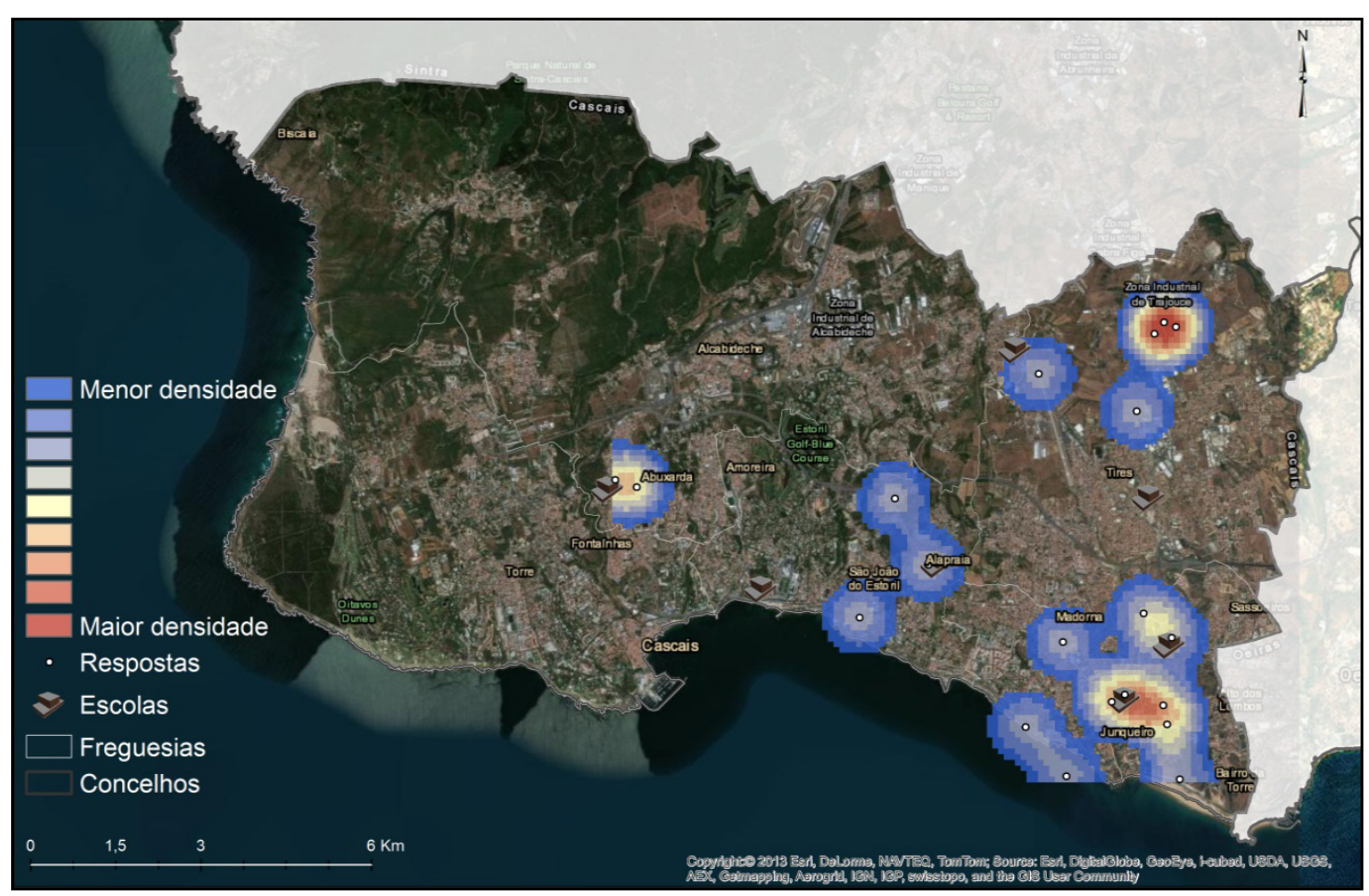

Figura 12 - Topofobias 5 - Locais onde te sentes inseguro (masculino). Fonte: Dados da pesquisa. 


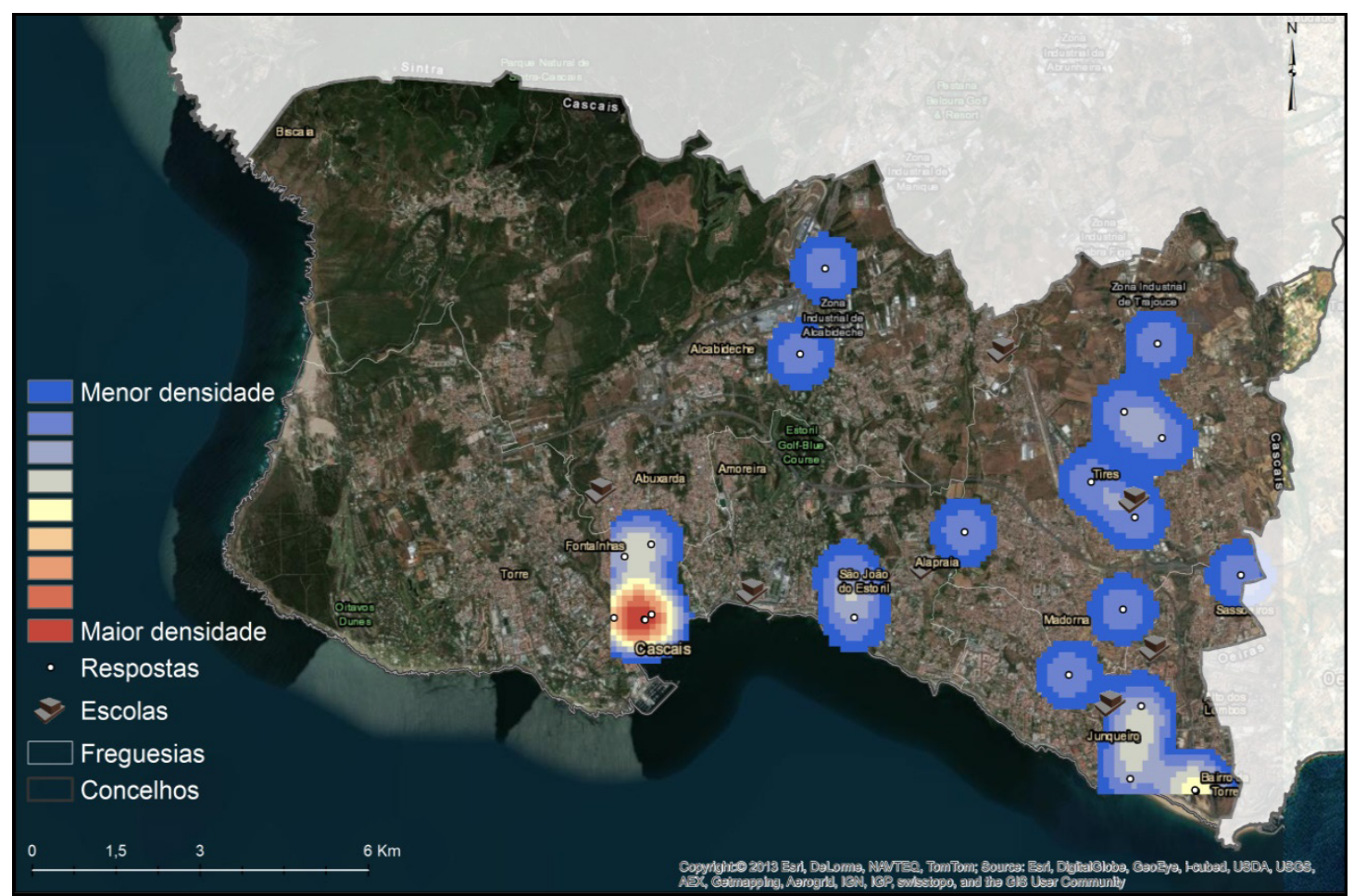

Figura 13 - Topofobias 6 -Locais onde te sentes inseguro (feminino). Fonte: Dados da pesquisa.

Em relação às Figuras 12 e 13, apesar de haver uma grande sobreposição entre géneros, é, mais uma vez, no mapa das raparigas que se verifica uma maior dispersão. Seria fácil dizer que tal significaria que as raparigas sentem mais lugares inseguros do que os rapazes. Isso pode ser verdade em termos absolutos, mas o mapa dos lugares de segurança também é mais plural para raparigas, o que torna essa conclusão menos óbvia. Talvez as raparigas tenham uma maior frequência dos espaços e, portanto, uma maior vivência e consciência territorial, e tal razão explique essa dispersão quer nos lugares de segurança, quer nos de insegurança. Por outro lado, quais são os fatores que transmitem insegurança a cada um dos géneros? A ameaça física para os rapazes e assédio para as raparigas é um dos motivos que permite estabelecer essa diferenciação e que poderia justificar a insegurança feminina em locais que não o são para os rapazes. 0 certo é que estes resultados requerem mais pesquisa.

Quadro 17 - Sociometrias territoriais de insegurança masculina (locais)

\begin{tabular}{|c|}
\hline Carcavelos - Zona-estrela $\star$ \\
\hline Zona Industrial Trajouce - Zona-estrela $\star$ \\
\hline Abuxarda \\
\hline
\end{tabular}

Fonte: Dados da pesquisa.

Quadro 18 - Sociometrias territoriais de segurança feminina (locais)

\begin{tabular}{|c|}
\hline Jumbo/Cascais Villa \\
\hline Bairo da Torre \\
\hline
\end{tabular}

Fonte: Dados da pesquisa.

Como já se referiu, os rapazes têm uma perceção mais concentrada em relação aos lugares de insegurança, identificando-se duas zonas-estrela: Carcavelos e a Zona Industrial de Trajouce. 0 destaque a zonas como o Jumbo e o Cascais Villa dá-se por serem espaços escuros, com lojas fechadas e sem vigilância. Os rapazes também destacam os bairros sociais como centros de insegurança, pela frequência e tráfico de droga, sugerindo mais policiamento (Quadro 17 e Quadro 18). 
Em relação às toponegligências (locais não referidos como topofobias ou topofilias), é notória uma grande mancha na zona oeste e noroeste do concelho, que inclui toda a área do Parque Natural de Sintra e Cascais, com algumas excepções na zona da praia do Guincho referidas como topofilias. Outra área negligenciada corresponde à zona a norte da A5, abrangendo as povoações de Adroana, Manique, Bicesse e Pau Gordo (Figura 14).

Ao se sobrepor os locais de residência dos inquiridos à mancha gerada por todas as respostas, é notória a prevalência de respostas em locais próximos da escola e dos locais de residência. Por essa razão, poder-se-á supor que a circulação dos jovens não é feita por todo o concelho, mas sim apenas nas proximidades das suas deslocações casa-escola, afastando-se um pouco mais quando se deslocam com os familiares.

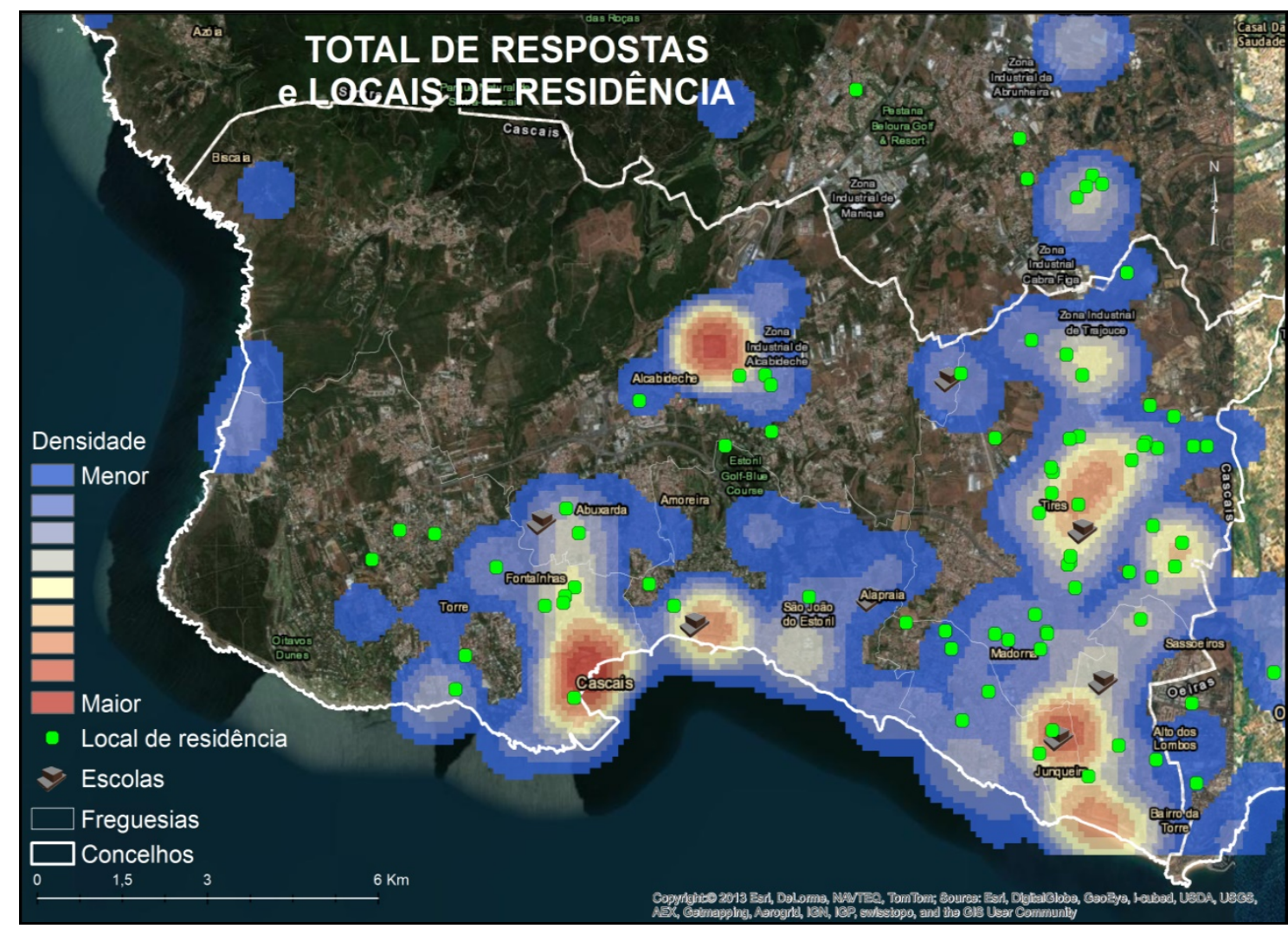

Figura 14 - Toponegligências. Fonte: dados da pesquisa.

\section{Propostas de mudança}

Finalmente, tendo a nossa pesquisa partido da premissa da ativação e participação cidadã como aspeto central, considerou-se os jovens inquiridos como especialistas ou peritos urbanos capazes de propor mudanças. Em relação aos lugares de que não gostam (Quadro 19), as propostas são as mais variadas, havendo quase que um programa completo de mudanças urbanísticas. Foi essa agregação que se fez numa primeira grande categoria. A mudança pretendida é clara: acessibilidades; mais espaços verdes e diminuição dos edifícios; demolição/refuncionalidade do Cascais Villa; aumentar o estacionamento; sinalização e lombas; mais iluminação; passeios; renovação e revitalização dos espaços; mais lojas; mais mesas; cor e aspeto dos prédios; restaurar casas; ciclovias; limpeza de praias e extensão do areal. A seguir só duas categorias são significativas: a segurança/policiamento e a mudança das pessoas, a qual inclui várias temáticas, desde a mudança de gerência de lojas à frequência por determinadas pessoas de determinados espaços. 
Quadro 19 - Propostas de Mudanças em lugares topofóbicos de gosto

\begin{tabular}{|c|c|}
\hline O que mudavas nos lugares de que não gostas & $\Sigma$ \\
\hline $\begin{array}{l}\text { Mudanças urbanísticas diversas: acessibilidade; mais espaços verdes e diminuição dos edifícios; tirava o } \\
\text { Cascais Villa; aumentar o estacionamento; sinalização e lombas; mais iluminação; passeios; renovação e } \\
\text { revitalização dos espaços; mais lojas; mais mesas; cor e aspeto dos prédios; restaurar casas; ciclovias; } \\
\text { limpeza de praias e extensão do areal }\end{array}$ & 25 \\
\hline Mais segurança/vigilância/ mais policiamento/ menos gangues nas ruas & 9 \\
\hline $\begin{array}{c}\text { Mudava as pessoas (a gerência; ambiente mais amigável; mudava muita gente; as pessoas que } \\
\text { frequentam; etc.) }\end{array}$ & 9 \\
\hline Tudo & 6 \\
\hline Outros & 6 \\
\hline Não responde & 8 \\
\hline
\end{tabular}

$\sum$ - somatório. Fonte: Dados da pesquisa.

Já nas propostas em relação aos espaços inseguros (Quadro 20), destaca-se a iluminação e a necessidade de maior segurança pela via do policiamento, pela construção de esquadras ou pela diminuição de armas nas ruas. Há depois propostas de mudanças diversas, desde alargamento de estradas, melhor organização do espaço, mais limpeza, mais passeios e passadeiras, abrigo para peões ou mais habitação ou habitação a preços mais elevados para manter a distinção. Há ainda a referência à mudança das pessoas.

Quadro 20 - Propostas de mudanças em lugares topofóbicos de segurança

\begin{tabular}{|c|c|}
\hline O que mudavas nos lugares inseguros & $\sum$ \\
\hline lluminação & 12 \\
\hline Mais Segurança/ construção de uma esquadra/mais policiamento/menos guns nas ruas & 12 \\
\hline $\begin{array}{c}\text { Mudanças urbanísticas várias: abrigo; mais habitação; habitação de valores elevados; passeios; } \\
\text { passadeiras; limpeza; alargar a estrada; melhor organização do espaço. }\end{array}$ & 11 \\
\hline Mudar as pessoas (retirar pessoas; fazer um espaço mais inclusivo; etc.) & 9 \\
\hline Mudar o ambiente & 2 \\
\hline Tudo & 1 \\
\hline Não dá para mudar & 1 \\
\hline Não responde & 8 \\
\hline
\end{tabular}

$\sum$ - somatório. Fonte: Dados da pesquisa.

\section{Discussão dos resultados}

Este relatório constitui o output de uma mediação por parte de in(ve)stigadores entre uma população específica e técnicos de um departamento de planejamento de uma autarquia. Tratou-se, antes de mais, de uma relação de cumplicidade e alinhamento entre pessoas com um mesmo objetivo: a promoção da participação cidadã. No entanto, ainda que a abertura e possibilidade de se realizar esta pesquisa revele já uma vontade em potenciar os processos participativos, o que transparece é que se está ainda numa fase de exploração de soluções. Ao mesmo tempo, não ficou claro como é que a participação alcançada por esta pesquisa pode ser utilizada na atualização do PDM da CMC.

Os resultados não constituíram uma grande surpresa para a autarquia, havendo, em alguns casos, uma confirmação de indícios que eram já conscientes. No entanto, a vantagem da utilização deste tipo de mapas sociais parece ser mais uma sistematização científica que legitima a ação do que uma tradução direta do mapeamento realizado para efeitos do PDM. Nesse sentido, as propostas de mudança aferidas por este instrumento, agregadas a propostas concretas efetuadas por alunos de escolas, parecem servir, antes de mais, a uma dinâmica de planejamento e mudanças em contínuo que é ainda utilizada de forma complementar aos atuais PDM.

A partir do momento em que a cultura de planejamento deixa de ser uma 'cultura de gabinete' (Souza, 2004), o planejamento torna-se mais aberto e continuado. Assim, as instituições que assumem esta nova cultura de planejamento estão mais aptas a receber estímulos relativos a participações e mudanças à la 
carte (a pedido) ou ad hoc (caso a caso), que vão ao encontro dos ensejos dos cidadãos. Cascais, enquanto autarquia com um dinamismo específico no panorama português, caraterizada por um historial de Boas Práticas de participação publica, corporiza um destes casos.

Desse modo, mais do que os resultados do mapeamento, é o processo relacional da realização da pesquisa o aspeto mais relevante para a discussão do potencial de utilização deste tipo de metodologias. Este processo relacional tem duas consequências: potenciar uma nova cultura de planejamento institucional; e preparar as populações para a participação e devolução da mesma. Neste quadro, os desafios da conciliação entre leituras participadas e ação técnica e política ainda só fazem sentido se discutidos no contexto das barreiras institucionais que se lhe colocam.

Assim, se é verdade que existe já o potencial dos dispositivos digitais em aumentar a participação cidadã, o que a aplicação desta pesquisa evidencia é que tal potencial tem de ser acompanhado por uma mudança da cultura de planejamento (Seixas, 2017). Embora haja sinais de que as mudanças em causa estejam já em curso, tal dinâmica parece estar ainda muito dependente da personificação dos projetos que decorre de peculiaridades de alinhamento entre determinadas autarquias e dinamizadores externos.

\section{Considerações finais}

Recorrendo a um instrumento de PPSIG, esta pesquisa verteu uma pluralidade de lugares de experiências num quadro de perceção objetiva, através de mapas de densidades de Kernel, a uma escala de planejamento municipal. 0 objetivo foi questionar os jovens sobre mobilidades, topofobias, topofilias, toponegligências e propostas de mudanças. Para além de evidenciar a aplicação de uma metodologia de participação cidadã, este exercício foi útil para discutir alguns dos desafios da conciliação entre leituras participadas e ação técnica e política na atualização dos PDM. Por outro lado, esta pesquisa contribuiu ainda como experiência de planejamento participado que poderá ser replicada em outras autarquias.

Ao nível das sociometrias alcançadas (Figura 15), um primeiro resultado é o mapa social de referência da juventude do concelho. Um lugar-estrela transversal a toda a vivência dos jovens é a zona central de Cascais e da Baía de Cascais. São ainda evidentes outras zonas-estrela, como o Estoril e a Praia de Carcavelos, assim como a zona de Trajouce e a zona de Tires.

Em relação às mobilidades, percebeu-se que cerca de metade dos jovens vai de carro para a escola, cerca de um terço de transporte público e menos de um quarto utiliza a mobilidade suave. Acresce que na mobilidade desejada casa-escola, a maioria dos jovens gostaria de ir de carro. Quanto às mobilidades complementares, o Cascais Shopping e a Baía de Cascais são os lugares/zonas-estrela de frequência autónoma, com pares/amigos ou com familiares. 0 convívio e o consumo são as razões que mais surgem para a frequência destes lugares.

Em relação às topofilias, a Baía de Cascais e a Praia de Carcavelos surgem como zonas-estrela na dimensão de 'gosto', enquanto na dimensão de segurança, a Zona Industrial de Tires (McDonalds/Burguer King) foi a mais referida. As topofobias centram-se na envolvente do Colégio Marista de Carcavelos (zona-estrela) na dimensão rejeição; já na insegurança houve uma certa dispersão, não havendo zonas-estrela, mas sendo a Zona Industrial Trajouce a mais referida. Há também zonas que foram rejeitadas duplamente, quer pelo gosto, quer pela segurança: a zona de Trajouce; a zona do Cascais Villa e Jumbo e determinadas zonas em Carcavelos. 


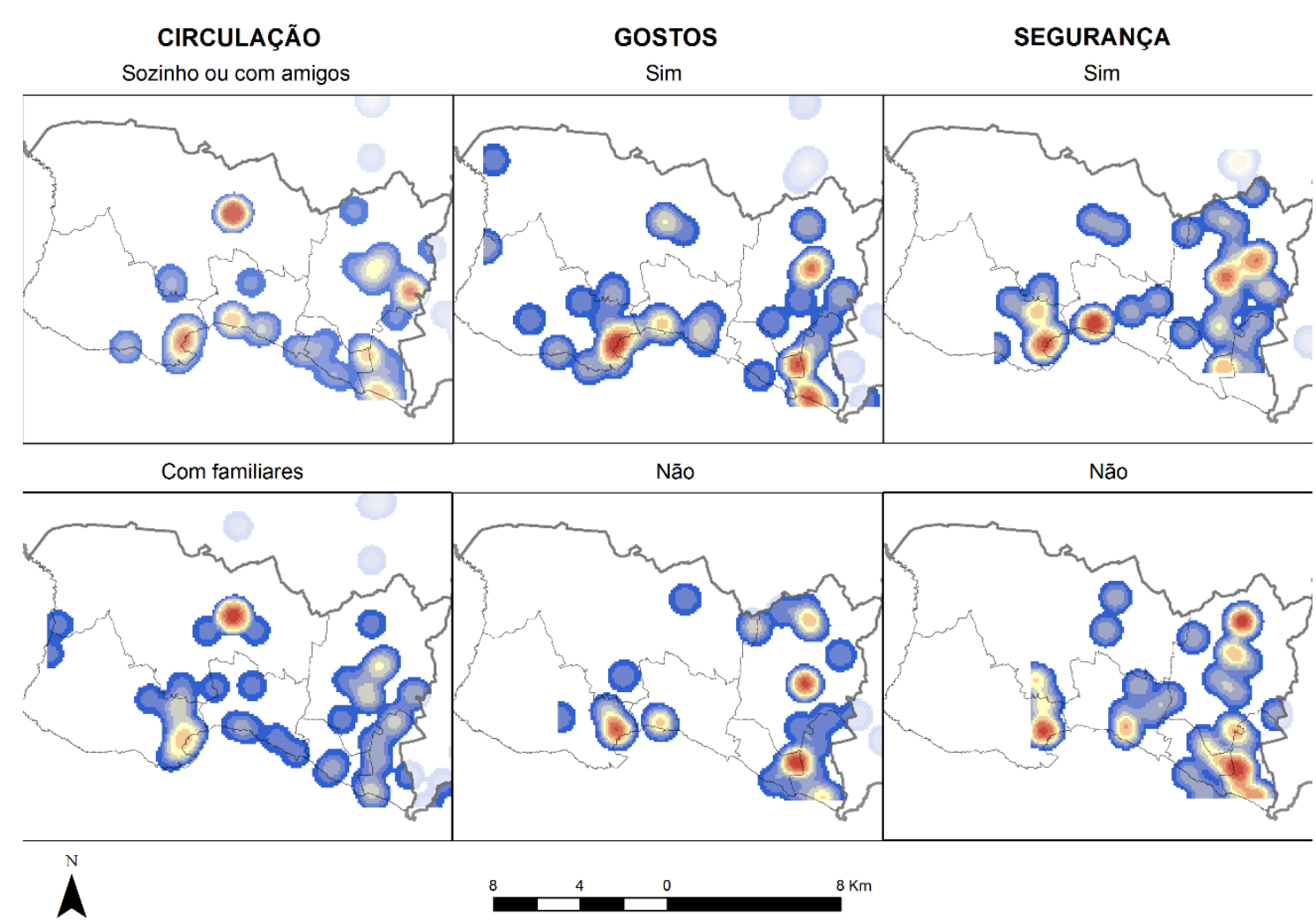

Figura 15 - Resumo comparativo de mobilidades, topofilias e topofobias. Fonte: Dados da pesquisa.

As escolas surgem na análise como centros importantes, havendo uma relação direta entre os mapas de densidades e as suas localizações: Alvide e Estoril, por um lado, e toda uma linha que vai da Escola de Manique, Frei Gonçalo de Azevedo, Escolas de Carcavelos e Maristas de Carcavelos, por outro. Um outro aspeto são as grandes zonas em branco que caracterizam toponegligências na perceção e vivências dos jovens inquiridos.

Por fim, e em relação aos desafios que resultaram da aplicação deste tipo de ferramentas como suporte a um planejamento estratégico mais efetivo, tais projetos parecem estar ainda muito dependentes da personificação dos mesmos em determinadas autarquias. É também nítido que se está ainda numa fase de exploração de soluções em que a utilização destas ferramentas é feita ainda de forma complementar e indireta na atualização dos PDM. Perceber como se pode aumentar a participação/adesão de grupos específicos a este tipo de instrumentos, e de que forma se pode verter mais diretamente estes dados nos PDM, são alguns dos desafios que ficam desta pesquisa e que devem ser alvo de investigações futuras.

\section{Referências}

Abadia, M., Dias, R. C., \& Seixas, P. C. (2019). Smart Cities no Brasil e em Portugal: o estado da arte. urbe. Revista Brasileira de Gestão Urbana, 11, 1-15.

Arnstein, S. R. (1969). A ladder of citizen participation. Journal of the American Planning Association, 35(4), $216-$ 224.

Atzmanstorfer, K., Resl, R., Eitzinger, A., \& Izurieta, X. (2014). The GeoCitizen-approach: community-based spatial planning: an Ecuadorian case study. Cartography and Geographic Information Science, 41(3), 248-259. http://dx.doi.org/10.1080/15230406.2014.890546. PMid:27019644.

Babelon, I., Ståhle, A., \& Balfors, B. (2017). Toward Cyborg PPGIS: exploring socio-technical requirements for the use of web-based PPGIS in two municipal planning cases, Stockholm region, Sweden. Journal of Environmental Planning and Management, 60(8), 1366-1390. http://dx.doi.org/10.1080/09640568.2016.1221798. 
Brown, G., \& Kyttä, M. (2014). Key issues and research priorities for public participation GIS (PPGIS): a synthesis based on empirical research. Applied Geography (Sevenoaks, England), 46, 122-136.

http://dx.doi.org/10.1016/j.apgeog.2013.11.004.

Bugs, G., \& Reis, A. T. L. (2016). Planejamento urbano participativo por meio da utilização de novas tecnologias: uma avaliação por especialistas. Urbe. Revista Brasileira de Gestão Urbana, 9(1), 110-123. http://dx.doi.org/10.1590/2175-3369.009.001.ao06.

Bunch, M. J., Kumaran, T. V., \& Joseph, R. (2012). Using Geographic Information Systems (GIS) for spatial planning and environmental management in India: critical considerations. International Journal of Applied Science and Technology, 2(2), 40-54.

Cohen, B. (2015, 8 de outubro). The 3 generations of Smart Cities: inside the development of the technology driven city. Fast Company. Recuperado em 20 janeiro de 2020, de https://www.fastcompany.com/3047795/the-3generations-of-smart-cities

Degbelo, A., Granell, C., Trilles, S., Bhattacharya, D., Casteleyn, S., \& Kray, C. (2016). Opening up Smart Cities: citizen-centric challenges and opportunities from GIScience. International Journal of Geo-Information, 5(2), 16. http://dx.doi.org/10.3390/ijgi5020016.

Ferrão, J. (2010). Governança e ordenamento do território: reflexões para uma governança territorial eficiente, justa e democrática. Prospetiva e Planejamento, 17, 129-139.

Ferrão, J. (2014). Ambiente e território: para uma nova geração de políticas públicas com futuro. In V. SoromenhoMarques, \& P. T. Pereira (Eds.), Afirmar o futuro: políticas públicas para Portugal, desenvolvimento sustentável, economia, território e ambiente (pp. 328-343). Lisboa: Fundação Calouste Gulbenkian.

Ferreira, F., \& Seixas, P. C. (2017). Portugal 2020 e o novo glossário de desenvolvimento territorial: territorialização ou neoinstitucionlização? Urbe. Revista Brasileira de Gestão Urbana, 9(3), 487-499. http://dx.doi.org/10.1590/2175-3369.009.003.ao08.

Ghilardi, L. (2001). Cultural planning and cultural diversity. In T. Bennett (Ed.), Differing diversities: transversal study on the theme of cultural policy and cultural diversity (pp. 1-17). Strasbourg: Council of Europe Publications.

Goodspeed, R. (2015). Smart Cities: moving beyond urban cybernetics to tackle wicked problems. Cambridge Journal of Regions, Economy and Society, 8(1), 79-92. http://dx.doi.org/10.1093/cjres/rsu013.

Lúcio, J., \& Rosa, G. (2004). A terceira vaga dos PDM’s e as questões estratégicas. In Atas do V Congresso da Geografia Portuguesa "Portugal: Territórios e Protagonistas. Lisboa: Associação Portuguesa de Geógrafos.

Portugal. (2014, 30 de maio). Lei nº 31/2014 de 8 de novembro. Lisboa: Diário da República, n. 104, série I.

Portugal. (2015, 14 de maio). Decreto-Lei nº 80/2015, de 14 de maio. Lisboa: Diário da Républica, n. 93, série I.

Portugal. (2017, 16 de agosto). Lei no 74/2017, de 16 de agosto. Lisboa: Diário da Républica, n. 157, série I.

Rzeszewski, M., \& Kotus, J. (2019). Usability and usefulness of internet mapping platforms in participatory spatial planning. Applied Geography, 103, 56-69. http://dx.doi.org/10.1016/j.apgeog.2019.01.001.

Seixas, P. C. (2017). Planejamento cultural e cultura do planejamento. In F. M. Cruz (Ed.), Cultura e cidade: abordagem multidisciplinar da cultura urbana (pp. 75-122). Natal: Universidade Federal do Rio Grande do Norte.

Seixas, P. C., Dias, R. C., \& Pereira, P. (2017). Uma cidade boa para viver: planejamento cultural e ciência cidadã no desenvolvimento urbano sustentável. A Obra Nasce, 12, 9-25.

Silva, G. A. B., David, P. L. D., \& Bianchi, G. (2017). A utilização do SIG para o planejamento urbano. ANAP Brasil, 10(21), 70-89. http://dx.doi.org/10.17271/19843240102120171675.

Souza, M. L. (2004). Mudar a cidade: uma introdução crítica ao planejamento e à gestão urbanos. Rio de Janeiro: Bertrand Brasil.

Tuan, Y. F. (1979). Landscapes offear. New York: Pantheon. 
Tuan, Y. F. (1990). Topophilia: a study of environmental perceptions, attitudes, and values. Columbia: Columbia University Press. Original work published 1974.

Tuan, Y. F. (2013). Espaço e lugar: a perspectiva da experiência. Londrina: Eduel. Original work published 1977.

Vaz, M. J. M., \& Pereira, É. M. (2010). Imagens urbanas: diretrizes de planejamento e desenho urbano baseadas na leitura popular de espaços públicos. urbe. Revista Brasileira de Gestão Urbana, 2(1), 29-42.

Editor: Fábio Duarte

Recebido: Set. 03, 2019

Aprovado: Mar. 07, 2020 